\title{
Micronutrient intake and status in Central and Eastern Europe compared with other European countries, results from the EURRECA network
}

\author{
Romana Novakovićl,* Adrienne EJM Cavelaars ${ }^{2}$, Geertruida E Bekkering ${ }^{3}$, \\ Blanca Roman-Viñas ${ }^{4}$, Joy $\mathrm{Ngo}^{4}$, Mirjana Gurinović ${ }^{1}$, Maria Glibetić ${ }^{\text {, Marina Nikolić }}$, \\ Mana Golesorkhi ${ }^{5}$, Marisol Warthon Medina ${ }^{6}, Z^{4}$ vonimir Šatalić ${ }^{7}$, Anouk Geelen², \\ Lluis Serra Majem ${ }^{4,8}$, Pieter van't Veer ${ }^{2}$ and Lisette CPGM de Groot ${ }^{2}$ \\ ${ }^{1}$ Institute for Medical Research, Centre of Research Excellence in Nutrition and Metabolism, University of \\ Belgrade, Tadeusa Koscuska 1, Belgrade 11000, Serbia: ${ }^{2}$ Division of Human Nutrition, Wageningen University \\ and Research Centre, Wageningen, The Netherlands: ${ }^{3}$ Catholic University of Leuven, Maurits Sabbe Library, \\ Leuven, Belgium: ${ }^{4}$ Community Nutrition Research Centre, Nutrition Research Foundation, Barcelona, Spain: \\ ${ }^{5}$ Department of Sport and Health Sciences, Oxford Brookes University, Oxford, UK: ${ }^{6}$ International Institute of \\ Nutritional Sciences and Food Safety Studies, Division of Sport Exercise \& Nutritional Sciences (SENS), \\ University of Central Lancashire, Preston, UK: ${ }^{7}$ Faculty of Food Technology and Biotechnology, University of \\ Zagreb, Zagreb, Croatia: ${ }^{8}$ Department of Clinical Sciences, University of Las Palmas de Gran Canaria, Las \\ Palmas de Gran Canaria, Spain
}

Submitted 26 September 2011: Final revision received 28 June 2012: Accepted 1 August 2012: First published online 20 September 2012

\begin{abstract}
Objective: To compare micronutrient intakes and status in Central and Eastern Europe (CEE) with those in other European countries and with reference values. Design: Review of the micronutrient intake/status data from open access and grey literature sources from CEE.

Setting: Micronutrients studied were folate, iodine, Fe, vitamin $\mathrm{B}_{12}$ and $\mathrm{Zn}$ (for intake and status) and $\mathrm{Ca}, \mathrm{Cu}$, Se, vitamin $\mathrm{C}$ and vitamin $\mathrm{D}$ (for intake). Intake data were based on validated dietary assessment methods; mean intakes were compared with average nutrient requirements set by the Nordic countries or the US Institute of Medicine. Nutritional status was assessed using the status biomarkers and cut-off levels recommended primarily by the WHO.

Subjects: For all population groups in CEE, the mean intake and mean/median status levels were compared between countries and regions: CEE, Scandinavia, Western Europe and Mediterranean.

Results: Mean micronutrient intakes of adults in the CEE region were in the same range as those from other European regions, with exception of $\mathrm{Ca}$ (lower in CEE). CEE children and adolescents had poorer iodine status, and intakes of Ca, folate and vitamin D were below the reference values.

Conclusions: CEE countries are lacking comparable studies on micronutrient intake/ status across all age ranges, especially in children. Available evidence showed no differences in micronutrient intake/status in CEE populations in comparison with other European regions, except for $\mathrm{Ca}$ intake in adults and iodine and Fe status in children. The identified knowledge gaps urge further research on micronutrient intake/status of CEE populations to make a basis for evidence-based nutrition policy.
\end{abstract}

\author{
Keywords \\ Micronutrient \\ Intake \\ Status \\ Central and Eastern Europe
}

Epidemiological research has shown socio-economic differences in health at all ages throughout Europe ${ }^{(1)}$. These inequalities in health have been reported to vary between countries and between socio-economic indicators $^{(2,3)}$. A possible explanation for these inequalities is a less optimal nutritional status in disadvantaged groups. For example, those with lower income suffer from higher rates of obesity, CVD and certain cancers that are linked to nutrition and $\operatorname{diet}^{(3,4)}$. This may be due to the fact that groups with limited economic means consume unhealthy foods that are cheap, energy-dense and nutrient-poor. Socio-economic position, as measured by income for instance, has been found to be one of the most important predictors of diet quality ${ }^{(4)}$.

Since the proportion of (economically) disadvantaged populations is higher in Central and Eastern European 
(CEE) countries ${ }^{(5-9)}$ it is highly relevant to evaluate whether differences in nutritional status may contribute to higher morbidity and mortality in CEE as compared with other European countries.

Assessment of dietary intake and nutritional status for European populations has been an emerging focus for the last two decades. However, current nutritional data are lacking for CEE populations ${ }^{(10,11)}$. This hinders research on nutritional health, which is needed to underpin nutrition policies for CEE populations with sizeable disadvantaged groups.

To fill the knowledge gap mentioned above, an additional approach is needed to deal with the standard searches conducted in known (open access) literature databases, i.e. the identification of commonly overlooked grey literature sources from CEE countries. So far, available nutritional data in CEE have often only been used for local health policies and have remained largely unexploited because they are either not published in an accessible manner or not available in English ${ }^{(1,12,13)}$.

In the present study, we compare micronutrient intakes and status in CEE with those in other European countries using both open access sources and grey literature sources. A better use of the latter data from CEE and its further exploitation will enable evaluation of the current nutritional situation of CEE populations to enhance regional policy making.

\section{Methods}

\section{EURRECA}

The present study was carried out within the context of the EURRECA (EURopean micronutrient RECommendations Aligned) Network of Excellence (http://www.eurreca.org). This network aims to advance methodology for setting micronutrient requirements and recommendations, and to identify vulnerable groups regarding micronutrient intake and status ${ }^{(14,15)}$. To answer our research question, we used the standardized dietary intake/status methodology recommended by EURRECA (more details are below). We focused on the EURRECA top ten micronutrients, prioritized on the basis of the amount of new scientific evidence, their relevance to public health and the variations in current micronutrient recommendations (vitamin $\mathrm{B}_{12}$, folate, $\mathrm{Fe}, \mathrm{Zn}$ and iodine (intake and status) and vitamin C, vitamin D, Ca, Se and Cu (intake only) $)^{(14)}$.

\section{Search metbodology}

Data on CEE countries were collected from PubMed and grey literature for intake and status, and from the WHO Vitamin and Mineral Nutrition Information System (VMNIS) database (http://www.who.int/vmnis/database/ en/) for status. For other European countries, we used available comprehensive reviews, primarily the European Nutrition and Health Report 2009 (ENHR II) for intake ${ }^{(16)}$ and PubMed and WHO VMNIS for status only. Review of the EFSA (European Food Safety Authority) Concise and Comprehensive European Food Consumption Databases did not result in additional data.

We searched for studies on intake and/or status in PubMed published from January 1990 until April 2010 using common medical subject headings (MeSH) and free text search terms: Micronutrients (listed) OR Biomarkers of status (listed) AND General intake/status terms with terms for adequacy, i.e. intake/status (requirement* or recommend* or adequacy or inadequacy or adequate or inadequate or cut point or threshold - in title and abstract) AND Country (CEE and non-CEE countries, listed).

The WHO Global Micronutrient Databases on Iodine Deficiency and Anaemia were used to collate information on iodine and Fe status.

To collect grey literature data on intake and or status from CEE countries, we cooperated with the United Nations University/Standing Committee on Nutrition Network for Capacity Development in Nutrition in Central and Eastern Europe (NCDN CEE) ${ }^{(17)}$. This network gathers nutritional researchers and public health specialists from all CEE countries, whose representatives were introduced to the purpose of the present study and with the search criteria for collection of grey literature at their NCDN annual meeting in November 2008. They were asked to identify potentially relevant data from their countries, translate the data to English if necessary and send them to us for further screening.

Titles and abstracts from every source were screened, and for potentially relevant papers and reports, full texts were retrieved. Subsequently, we assessed which studies were eligible for our study using the following inclusion criteria.

1. The population studied should be representative for the country and apparently healthy, and data gathered should have had a sample size of at least 100 per

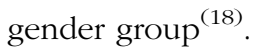

2. The study should include information on mean usual micronutrient intake and apply one of the following dietary intake methods (EURRECA best practice dietary intake methods): a validated FFQ or validated diet history; a food diary/register with at least $7 \mathrm{~d}$; three or more $24 \mathrm{~h}$ recalls or registers; or three or fewer $24 \mathrm{~h}$ recalls with an adjustment for intra-individual variability $^{(19)}$. Initially, these criteria were applied to both CEE and non-CEE data; however, keeping this condition for CEE data would have resulted in very few studies for assessment. For this reason, CEE studies on intake that used one or more $24 \mathrm{~h}$ recalls (with no adjustments for intra-individual variability) or other dietary assessment methods were included as well. If more than one country-representative study that fulfilled the inclusion criteria were available, the choice of the study to be presented graphically was made by 
giving preference to the one that was most recently published.

3. Regarding nutritional status, data gathered should include information on mean or median status using best practice biomarkers defined in the context of EURRECA: Hb, serum/plasma ferritin or serum/plasma transferrin receptor for Fe; erythrocyte (red cell) folate, serum/plasma folate or serum/plasma homocysteine for folate; serum/plasma total $\mathrm{B}_{12}$, serum/plasma methylmalonic acid or serum/plasma holotranscobalamin for vitamin $\mathrm{B}_{12}$; serum/plasma $\mathrm{Zn}$ for $\mathrm{Zn}$; and urinary iodine ( $24 \mathrm{~h}$ or spot), serum or dried whole blood spot thyroglobulin or serum thyroid-stimulating hormone for iodine ${ }^{(20-27)}$.

\section{Data analyses}

We compared mean intakes and median (or mean) status levels between countries, between regions and with external reference values to evaluate differences between countries and indications for inadequacies. When several studies were available for one country, studies were ranked for their eligibility considering representativeness of the sample for the country, dietary assessment method used and year of the study (most recent were given preference).

To study regional variations in micronutrient intake and/or status, Europe was divided into four geographical regions: (i) CEE (Albania, Bosnia-Herzegovina, Bulgaria, Croatia, Czech Republic, Estonia, Latvia, Lithuania, Hungary, Macedonia, Montenegro, Poland, Romania, Serbia, Slovakia and Slovenia); (ii) Mediterranean (Greece, Italy, Portugal and Spain); (iii) Western Europe (Austria, Belgium, France, Germany, Ireland, The Netherlands, Switzerland and the UK); and (iv) Scandinavia (Denmark, Finland, Iceland, Norway and Sweden).

Regional comparisons were made when data for a specific micronutrient and population group were available for at least three CEE countries. This comparison included the calculation of weighed mean regional intakes and median status levels, plotting of country means (medians) and subsequently the description of: (i) differences in intake and/or status across European regions and (ii) observed mean intake and/or status in CEE countries in contrast to nutritional reference values. Variables considered in the description were differences in dietary assessment method (checked also by differences in mean daily energy consumption) and study population. In cases where data were available for fewer than three CEE countries, data from CEE countries were compared with the data from other European countries published in ENHR II ${ }^{(16)}$ or from single studies, selecting those with the most comparable data (regarding age group, status biomarker, dietary assessment method and year of the study).

To evaluate whether there is an indication for inadequacy in micronutrient intake, the mean usual intake was compared with the ANR (Average Nutrient Requirement; amount of nutrient which is sufficient for $50 \%$ of the apparently healthy population) derived for the Nordic countries (Nordic Nutrition Recommendations, NNR) ${ }^{(28,29)}$, as these are the most recent reference values set for a series of European countries.* If an ANR for a micronutrient was not set by NNR (Ca and vitamin D in adults, all micronutrients in children), the ANR published for the USA/Canada by the US Institute of Medicine was used ${ }^{(22)}$. Relevant ANR are given in the figure captions. To assess adequacy of levels of status markers, we used guidance on cut-off values from EURRECA experts ${ }^{(30-33)}$. These cut-off values were based on key references mostly published by the WHO in cooperation with other institutions ${ }^{(20-27)}$. The specific values used are added to figure captions, table footnotes or text where applicable.

\section{Results}

\section{Literature search and data availability}

The search on micronutrient intake/status for all age ranges in CEE in the PubMed database resulted in 1949 titles and abstracts, out of which 121 were left after screening for potential relevance. The key reason for exclusion was that studies did not report mean intake or status. For one hundred and thirteen, full manuscripts were obtained and checked for compliance with the inclusion criteria; eight studies were inaccessible. Finally, thirty-eight studies were kept for further analysis, of which the grey literature added nine studies in total and contributed primarily data on micronutrient intake in adults. The WHO VMNIS database provided thirty-four studies on iodine and Fe status. A detailed overview of the study characteristics is given in Table 1 .

\section{Comparison of micronutrient intakes}

Micronutrient intake data were most abundant for $\mathrm{Ca}$, folate, $\mathrm{Fe}$, vitamin $\mathrm{B}_{12}$, vitamin $\mathrm{C}$ and vitamin $\mathrm{D}$ in adults. Figures 1 to 6 plot the mean micronutrient intakes (with $95 \%$ confidence intervals) geographically (by country in four regions) and information is given on the dietary assessment method, age range of the study population, number of subjects and mean energy intake for males and females.

Observed mean Ca intake (Fig. 1) among females in CEE countries (pooled estimated mean: $869 \mathrm{mg} / \mathrm{d}$ ) was in general lower than those in other European countries. The pooled means were 978, 1006 and $881 \mathrm{mg} / \mathrm{d}$ for Scandinavian, Western European and Mediterranean countries, respectively. The observed mean intake among

\footnotetext{
* Although more sophisticated methods are available for assessment of inadequacy such as the EAR (Estimated Average Requirement) cut-point method $^{(27)}$, we only compared mean levels with a reference value, as the more advanced methods use standard deviations. Standard deviations vary considerably by assessment method and request a higher comparability of measurement between countries.
} 
Table 1 Characteristics of studies included in the present review*

\begin{tabular}{|c|c|c|c|c|c|c|}
\hline Country & Study name & Study year & Population group & No. of subjects; sex & $\begin{array}{l}\text { Food intake method } \\
\text { or Status measure }\end{array}$ & $\begin{array}{l}\text { Micronutrients } \\
\text { included in the study }\end{array}$ \\
\hline \multirow[t]{2}{*}{ Albania } & $\begin{array}{l}\text { lodine treatment in children with subclinical hypothyroidism } \\
\text { due to chronic iodine deficiency decreases thyrotropin and } \\
\text { C-peptide concentrations and improves the lipid profile }{ }^{(46)}\end{array}$ & 2009 & $\begin{array}{l}\text { Children aged } \\
10 \pm 2 \text { years }\end{array}$ & $133 \mathrm{M} \& \mathrm{~F}$ & Urinary iodine & lodine \\
\hline & $\begin{array}{l}\text { lodine supplementation improves cognition in iodine-deficient } \\
\text { school children in Albania: a randomized, controlled, } \\
\text { double-blind study }(47)\end{array}$ & 2006 & $\begin{array}{l}\text { Children aged } \\
10-12 \text { years }\end{array}$ & $303 \mathrm{M} \& \mathrm{~F}$ & Urinary iodine & lodine \\
\hline Bosnia & $\begin{array}{l}\text { Thyroid volume and urinary iodine excretion in school children } \\
\text { in North-Eastern Bosnia }{ }^{(48)}\end{array}$ & 2008 & $\begin{array}{l}\text { Children aged } 7-14 \\
\quad \text { years }\end{array}$ & $513 \mathrm{M} \& \mathrm{~F}$ & Urinary iodine & lodine \\
\hline \multirow[t]{3}{*}{ Bulgaria } & $\begin{array}{l}\text { Evaluation of endemic goiter prevalence in Bulgarian } \\
\text { schoolchildren results from national strategies for } \\
\text { prevention and control of iodine-deficiency disorders }\end{array}$ & 2007 & $\begin{array}{l}\text { Boys and girls aged } \\
8-15 \text { years }\end{array}$ & $\begin{array}{l}274 \mathrm{M} \\
209 \mathrm{~F}\end{array}$ & Urinary iodine & lodine \\
\hline & tAgeingNutrition ${ }^{(50)}$ & 2006 & $>55$ years & $\begin{array}{l}186 \mathrm{M} \\
194 \mathrm{~F}\end{array}$ & $24 \mathrm{hR}$ & Vitamin C \\
\hline & $\begin{array}{l}\text { tNational study of urinary iodine excretion - biomarker of } \\
\text { lodine nutrition }{ }^{(51)}\end{array}$ & 2003 & $\begin{array}{l}\text { Children aged } 7-11 \\
\text { years; pregnant } \\
\text { women }\end{array}$ & $\begin{array}{l}809 \mathrm{M} \& \mathrm{~F} \\
355 \mathrm{~F}\end{array}$ & Urinary iodine & lodine \\
\hline \multirow[t]{5}{*}{ Croatia } & $\begin{array}{l}\text { Diet quality in Croatian university students: energy, } \\
\text { macronutrient intakes according to gender }{ }^{(52)}\end{array}$ & 2007 & $\begin{array}{l}\text { Males and females } \\
\text { aged } 18-30 \text { years }\end{array}$ & $\begin{array}{l}183 \mathrm{M} \\
480 \mathrm{~F}\end{array}$ & FFQ quantified & $\begin{array}{l}\mathrm{Ca}, \mathrm{Cu}, \text { folate, } \mathrm{Fe} \\
\mathrm{Se}, \text { vitamin } \mathrm{B}_{12} \\
\text { vitamin } \mathrm{C}, \mathrm{Zn}\end{array}$ \\
\hline & $\begin{array}{l}\text { Dietary habits and folate status in women of childbearing age } \\
\text { in Croatia } \\
(53)\end{array}$ & 2006 & $\begin{array}{l}\text { Females aged } \\
20-30 \text { years }\end{array}$ & $100 \mathrm{~F}$ & $\begin{array}{l}2 \times 24 \mathrm{hR} ; \text { serum } \\
\text { folate }\end{array}$ & Folate \\
\hline & $\begin{array}{l}\text { Calcium intake, food sources and seasonal variations in } \\
\text { Eastern Croatia }\end{array}$ & 2005 & $\begin{array}{l}\text { Males and females } \\
\text { aged } 18-55 \text { years }\end{array}$ & $\begin{array}{l}46 \mathrm{M} \\
115 \mathrm{~F}\end{array}$ & FFQ & $\mathrm{Ca}$ \\
\hline & $\begin{array}{l}\text { Comparison of dietary habits in the urban and rural Croatian } \\
\text { schoolchildren }{ }^{(55)}\end{array}$ & 2004 & $\begin{array}{l}\text { Children aged } 8-16 \\
\text { years }\end{array}$ & $\begin{array}{l}315 \text { (urban) } \\
163 \text { (rural) }\end{array}$ & FFQ quantified & $\begin{array}{l}\text { Ca, folate, } \mathrm{Fe}, \\
\mathrm{Se}, \text { vitamin } \mathrm{B}_{12}, \\
\text { vitamin } \mathrm{C}, \\
\text { vitamin } \mathrm{D}, \mathrm{Zn}\end{array}$ \\
\hline & $\begin{array}{l}\text { Ultrasound bone measurement in children and adolescents: } \\
\text { correlation with nutrition, puberty, anthropometry, and } \\
\text { physical activity }{ }^{(56)}\end{array}$ & 2003 & $\begin{array}{l}\text { Boys and girls aged } \\
7-10 \text { years; boys } \\
\text { and girls aged } \\
15-17 \text { years }\end{array}$ & $\begin{array}{l}120 \mathrm{M} \\
122 \mathrm{~F} \\
112 \mathrm{M} \\
147 \mathrm{~F}\end{array}$ & $\begin{array}{l}\text { Semi-quantitative } \\
\text { FFQ }\end{array}$ & $\mathrm{Ca}$ \\
\hline \multirow[t]{5}{*}{$\begin{array}{l}\text { Czech } \\
\text { Republic }\end{array}$} & $\begin{array}{l}\text { Dietary habits in three Central and Eastern European } \\
\text { countries: the HAPIEE study }{ }^{(57)}\end{array}$ & 2009 & $\begin{array}{l}\text { Males and females } \\
\text { aged } 45-69 \text { years }\end{array}$ & $\begin{array}{l}3690 \mathrm{M} \\
4223 \mathrm{~F}\end{array}$ & FFQ validated & $\begin{array}{l}\text { Ca, folate, } \mathrm{Fe} \text {, } \\
\text { vitamin } \mathrm{C}\end{array}$ \\
\hline & $\begin{array}{l}\text { Health behaviors, nutritional status, and anthropometric } \\
\text { parameters of Roma and non-Roma mothers and their } \\
\text { infants in the Czech Republic } \\
\text { (58) }\end{array}$ & 2009 & Lactating women & $151 \mathrm{~F}$ & Serum folate & Folate \\
\hline & lodine in early pregnancy - is there enough $?^{(59)}$ & 2008 & $\begin{array}{l}\text { Pregnant women } \\
\text { aged } 17-41 \text { years }\end{array}$ & $168 \mathrm{~F}$ & Urinary iodine & lodine \\
\hline & $\begin{array}{l}\text { Actual levels of soy phytoestrogens in children correlate with } \\
\text { thyroid laboratory parameters }{ }^{(60)}\end{array}$ & 2006 & $\begin{array}{l}\text { Boys and girls aged } \\
8-15 \text { years }\end{array}$ & $\begin{array}{l}129 \mathrm{M} \\
139 \mathrm{~F}\end{array}$ & Urinary iodine & lodine \\
\hline & $\begin{array}{l}\text { Mild hyperhomocysteinaemia is associated with increased } \\
\text { aortic stiffness in general population }{ }^{(61)}\end{array}$ & 2006 & $\begin{array}{l}\text { Males and females } \\
\text { aged } 25-65 \text { years }\end{array}$ & $\begin{array}{l}126 \mathrm{M} \\
125 \mathrm{~F}\end{array}$ & $\begin{array}{l}\text { Homocysteine; } \\
\text { serum folate; } \\
\text { serum vitamin } B_{12}\end{array}$ & Folate, vitamin $\mathrm{B}_{12}$ \\
\hline
\end{tabular}




\begin{tabular}{|c|c|c|c|c|c|c|}
\hline Country & Study name & Study year & Population group & No. of subjects; sex & $\begin{array}{l}\text { Food intake method } \\
\text { or Status measure }\end{array}$ & $\begin{array}{l}\text { Micronutrients } \\
\text { included in the study }\end{array}$ \\
\hline & Genetic determinants of folate status in Central Bohemia ${ }^{(62)}$ & 2005 & $\begin{array}{l}\text { Males and females } \\
\text { aged } 18-65 \text { years }\end{array}$ & $\begin{array}{l}250 M \\
261 \mathrm{~F}\end{array}$ & $\begin{array}{l}\text { Serum folate; serum } \\
\text { homocysteine; } \\
\text { erythrocyte folate; } \\
\text { serum vitamin } B_{12}\end{array}$ & Folate, vitamin $\mathrm{B}_{12}$ \\
\hline & $\begin{array}{l}\text { INAA of serum zinc of inhabitants in five regions of the Czech } \\
\text { Republic }^{(63)}\end{array}$ & 1999 & $\begin{array}{l}\text { Boys and girls aged } \\
10 \text { years; males } \\
\text { aged } 36-49 \\
\text { years; females } \\
\text { aged } 36-49 \text { years } \\
\text { and } 50-65 \text { years }\end{array}$ & $\begin{array}{l}90 \mathrm{M} \\
104 \mathrm{~F} \\
118 \mathrm{M} \\
118 \mathrm{~F} \\
106 \mathrm{~F}\end{array}$ & Serum zinc & Zinc \\
\hline \multirow[t]{4}{*}{ Estonia } & $\begin{array}{l}\text { The reference limits and cut-off value for serum soluble } \\
\text { transferrin receptors for diagnosing iron deficiency in } \\
\text { infants }{ }^{(64)}\end{array}$ & 2008 & 9-12 months & $146 \mathrm{M} \& \mathrm{~F}$ & Serum transferrin & $\mathrm{Fe}$ \\
\hline & $\begin{array}{l}\text { Prevalence and causes of iron deficiency anemias in infants } \\
\text { aged } 9 \text { to } 12 \text { months in Estonia }{ }^{(65)}\end{array}$ & 2007 & $9-12$ months & $171 \mathrm{M} \& \mathrm{~F}$ & $\begin{array}{l}\mathrm{Hb} \text {; serum } \\
\text { transferrin; serum } \\
\text { ferritin }\end{array}$ & $\mathrm{Fe}$ \\
\hline & tAgeingNutrition ${ }^{(50)}$ & 2006 & $>55$ years & $\begin{array}{l}126 \mathrm{M} \\
190 \mathrm{~F}\end{array}$ & $24 \mathrm{hR}$ & $\begin{array}{l}\text { Folate, vitamin } B_{12} \\
\text { vitamin } D\end{array}$ \\
\hline & $\begin{array}{l}\text { tNutrition and Lifestyle in the Baltic Republics - Summary } \\
\text { Report }^{(66)}\end{array}$ & 1999 & $\begin{array}{l}\text { Males and females } \\
\text { aged } 19-64 \text { years }\end{array}$ & $\begin{array}{l}900 \mathrm{M} \\
1115 \mathrm{~F}\end{array}$ & $24 \mathrm{hR}$ & $\begin{array}{l}\text { Ca, vitamin } \mathrm{C}, \mathrm{Fe} \text {, } \\
\text { folate }\end{array}$ \\
\hline \multirow[t]{6}{*}{ Hungary } & $\begin{array}{l}\text { Dietary habits of schoolchildren: representative survey in } \\
\text { metropolitan elementary schools: Part } 2^{(67)}\end{array}$ & 2007 & $\begin{array}{l}\text { Boys and girls aged } \\
11-14 \text { years }\end{array}$ & $\begin{array}{l}124 \mathrm{M} \\
111 \mathrm{~F}\end{array}$ & 3dDR & $\begin{array}{l}\mathrm{Ca}, \mathrm{Cu} \text {, folate, } \mathrm{Fe}, \\
\text { vitamin } \mathrm{B}_{12}, \\
\text { vitamin } \mathrm{C}, \text { vitamin } \\
\mathrm{D}, \mathrm{Zn}\end{array}$ \\
\hline & $\begin{array}{l}\text { tReport on Periconceptional Folic Acid Supplementation for } \\
\text { Hungary }\end{array}$ & 2007 & $\begin{array}{r}\text { Females aged } \\
18-59 \text { years }\end{array}$ & $352 \mathrm{~F}$ & $3 \times 24 h R$ & Folate \\
\hline & †AgeingNutrition ${ }^{(50)}$ & 2006 & $>55$ years & $\begin{array}{l}93 \mathrm{M} \\
159 \mathrm{~F}\end{array}$ & $24 \mathrm{hR}$ & $\begin{array}{l}\text { Vitamin } B_{12} \\
\quad \text { vitamin } C\end{array}$ \\
\hline & Dietary survey in Hungary, 2003-2004 ${ }^{(69)}$ & 2005 & $\begin{array}{l}\text { Males and females } \\
\text { aged } 18-60+ \\
\text { years }\end{array}$ & $\begin{array}{l}473 \mathrm{M} \\
706 \mathrm{~F}\end{array}$ & $24 \mathrm{hR}$ & $\begin{array}{l}\mathrm{Ca}, \mathrm{Cu}, \text { folate, } \mathrm{Fe}, \\
\text { vitamin } \mathrm{B}_{12}, \\
\text { vitamin } \mathrm{C}, \\
\text { vitamin } \mathrm{D}, \mathrm{Zn}\end{array}$ \\
\hline & $\begin{array}{l}\text { Prevalence and seasonal variation of hypovitaminosis } \mathrm{D} \text { and } \\
\text { its relationship to bone metabolism in community dwelling } \\
\text { postmenopausal Hungarian women }\end{array}$ & 2003 & $\begin{array}{l}\text { Females aged } \\
41-91 \text { years }\end{array}$ & $319 \mathrm{~F}$ & FFQ validated & $\mathrm{Ca}$ \\
\hline & $\begin{array}{l}\text { tNutrition survey of the Hungarian population in a randomized } \\
\text { trial between } 1992-1994^{(71)}\end{array}$ & 1996 & $\begin{array}{l}\text { Males aged } \\
18-34 \text { years and } \\
35-59 \text { years; } \\
\text { females aged } \\
18-34 \text { years, } \\
35-54 \text { years and } \\
\text { >55 years }\end{array}$ & $\begin{array}{l}338 \mathrm{M} \\
730 \mathrm{M} ; \\
343 \mathrm{~F} \\
938 \mathrm{~F} \\
105 \mathrm{~F}\end{array}$ & $\begin{array}{l}\text { 24hR; } \mathrm{Hb} \text {; serum } \\
\quad \text { folate; serum } \mathrm{Zn}\end{array}$ & $\begin{array}{l}\mathrm{Ca}, \mathrm{Cu} \text {, folate, } \mathrm{Fe} \\
\text { vitamin } \mathrm{C}, \mathrm{Zn}\end{array}$ \\
\hline Latvia & $\begin{array}{l}\text { tNutrition and Lifestyle in the Baltic Republics - Summary } \\
\text { Report }^{(66)}\end{array}$ & 1999 & $\begin{array}{l}\text { Males and females } \\
\text { aged } 19-64 \text { years }\end{array}$ & $\begin{array}{l}1065 \mathrm{M} \\
1235 \mathrm{~F}\end{array}$ & $24 \mathrm{hR}$ & $\mathrm{Ca}, \mathrm{Fe}$, vitamin $\mathrm{C}$ \\
\hline Lithuania & $\begin{array}{l}\text { Prognostic value of reticulocyte haemoglobin content to } \\
\text { diagnose iron deficiency in } 6-24-\text { month-old children }{ }^{(72)}\end{array}$ & 2008 & 6-24 months & $180 \mathrm{M} \& \mathrm{~F}$ & $\mathrm{Hb}$ & $\mathrm{Fe}$ \\
\hline
\end{tabular}


Table 1 Continued

\begin{tabular}{|c|c|c|c|c|c|c|}
\hline Country & Study name & Study year & Population group & No. of subjects; sex & $\begin{array}{l}\text { Food intake method } \\
\text { or Status measure }\end{array}$ & $\begin{array}{l}\text { Micronutrients } \\
\text { included in the study }\end{array}$ \\
\hline & $\begin{array}{l}\text { tNutrition and Lifestyle in the Baltic Republics - Summary } \\
\text { Report }^{(66)}\end{array}$ & 1999 & $\begin{array}{l}\text { Males and females } \\
\text { aged } 20-65 \text { years }\end{array}$ & $\begin{array}{l}2606 \mathrm{M} \\
1132 \mathrm{~F}\end{array}$ & $24 \mathrm{hR}$ & $\mathrm{Ca}, \mathrm{Fe}$, vitamin $\mathrm{C}$ \\
\hline \multirow[t]{8}{*}{ Poland } & $\begin{array}{l}\text { lodine excretion with urine and thyrotrophic hormone } \\
\text { concentration in normal and complicated pregnancies in the } \\
\text { industrial region of iodine deficiency }{ }^{73)}\end{array}$ & 2006 & $\begin{array}{l}\text { Pregnant women } \\
\text { aged } 28 \cdot 2 \pm 6 \cdot 4 \\
\text { years }\end{array}$ & $104 \mathrm{~F}$ & Urinary iodine & lodine \\
\hline & $\begin{array}{l}\text { tFood consumption of low income groups in Poland and } \\
\text { Belgium }^{(74)}\end{array}$ & 2007 & $\begin{array}{l}\text { Males and females } \\
\text { aged } 19-59 \text { years }\end{array}$ & $240 \mathrm{M} \& \mathrm{~F}$ & $24 \mathrm{hR}$ and $\mathrm{FFQ}$ & $\begin{array}{l}\mathrm{Ca}, \mathrm{Cu}, \mathrm{Fe} \text {, vitamin } \\
\mathrm{B}_{12}, \text { vitamin } \mathrm{C}, \mathrm{Zn}\end{array}$ \\
\hline & $\begin{array}{l}\text { +Wartość energetyczna i odżywcza diety dorosłych } \\
\text { mieszkańców Polski. Wyniki programu WOBASZ } \\
\text { (unpublished results, obtained by personal correspondence } \\
\text { with Dr Elzbieta Sygnowska, } 10 \text { November } 2010)^{(75)}\end{array}$ & 2010 & $\begin{array}{l}\text { Males and females } \\
\text { aged } 20-74 \text { years }\end{array}$ & $\begin{array}{l}3132 \mathrm{M} \\
3529 \mathrm{~F}\end{array}$ & 24hR; homocysteine & $\begin{array}{l}\mathrm{Ca}, \mathrm{Cu}, \text { folate, } \mathrm{Fe} \\
\text { vitamin } \mathrm{B}_{12}, \\
\text { vitamin } \mathrm{C} \\
\text { vitamin } \mathrm{D}, \mathrm{Zn}\end{array}$ \\
\hline & $\begin{array}{l}\text { Dietary habits in three Central and Eastern European } \\
\text { countries: the HAPIEE study }{ }^{(57)}\end{array}$ & 2009 & $\begin{array}{l}\text { Males and females } \\
\text { aged } 45-69 \text { years }\end{array}$ & $\begin{array}{l}4815 \mathrm{M} \\
5044 \mathrm{~F}\end{array}$ & FFQ validated & $\begin{array}{l}\text { Ca, folate, } \mathrm{Fe} \\
\text { vitamin } \mathrm{C}\end{array}$ \\
\hline & $\begin{array}{l}\text { Polish Food Consumption and Anthropometric Survey 2000: } \\
\text { comparison between household budget survey and } 24-\mathrm{h} \\
\text { recall data in a nationally representative sample of Polish } \\
\text { households }^{(76)}\end{array}$ & 2005 & $\begin{array}{l}\text { All age groups } \\
\text { (0-96 years) }\end{array}$ & $3716 \mathrm{M} \& \mathrm{~F}$ & $24 \mathrm{hR}$ & $\begin{array}{l}\mathrm{Ca}, \mathrm{Cu}, \mathrm{Fe} \text {, vitamin } \\
\quad \mathrm{C}, \mathrm{Zn}\end{array}$ \\
\hline & $\begin{array}{l}\text { Effectiveness of the iodine prophylaxis model adopted in } \\
\text { Poland }{ }^{(77)}\end{array}$ & 2008 & $\begin{array}{l}\text { Boys and girls aged } \\
6-12 \text { years }\end{array}$ & $\begin{array}{l}1450 \mathrm{M} \\
1563 \mathrm{~F}\end{array}$ & Urinary iodine & lodine \\
\hline & $\begin{array}{l}\text { Increased prevalence of hyperthyroidism as an early and } \\
\text { transient side-effect of implementing iodine prophylaxis }{ }^{(78)}\end{array}$ & 2007 & $\begin{array}{l}\text { Males and females } \\
\text { aged }>16 \text { years }\end{array}$ & $\begin{array}{l}491 \mathrm{M} \\
933 \mathrm{~F}\end{array}$ & Urinary iodine & lodine \\
\hline & $\begin{array}{l}\text { Comparative analysis of zinc status, food products' frequency } \\
\text { intake and food habits of } 11 \text {-year-old healthy children }{ }^{(79)}\end{array}$ & 2002 & $\begin{array}{l}\text { Children aged } \\
11 \text { years }\end{array}$ & $157 \mathrm{M} \& \mathrm{~F}$ & Serum Zn & $\mathrm{Zn}$ \\
\hline \multirow[t]{2}{*}{ Serbia } & $\begin{array}{l}\text { tNational Survey of the Biological Impact of Universal Salt } \\
\text { Iodisation in the Population of Serbia } 2007^{(80)}\end{array}$ & 2007 & $\begin{array}{l}\text { Children aged } \\
6-14 \text { years }\end{array}$ & $1745 \mathrm{M} \& \mathrm{~F}$ & Urinary iodine & lodine \\
\hline & $\begin{array}{l}\text { +Yugoslav study of atherosclerosis precursors in } \\
\text { schoolchildren in Serbia from } 1998-2003^{(36)}\end{array}$ & 2003 & $\begin{array}{l}\text { Boys and girls aged } \\
15 \text { years; males } \\
\text { and females aged } \\
10-15 \text { years, } \\
30-59 \text { years and } \\
60-75 \text { years }\end{array}$ & $\begin{array}{c}1984 \mathrm{M} \\
1859 \mathrm{~F} ; \\
1225 \mathrm{M} \\
1173 \mathrm{M} \\
147 \mathrm{M} \\
1228 \mathrm{~F} \\
1227 \mathrm{~F} \\
246 \mathrm{~F}\end{array}$ & $\begin{array}{l}\text { HFCS (7 d record); } \\
\text { Hb }\end{array}$ & $\begin{array}{l}\mathrm{Ca}, \mathrm{Cu}, \text { folate, } \\
\text { lodine, } \mathrm{Fe}, \\
\text { vitamin } \mathrm{B}_{12}, \\
\text { vitamin } \mathrm{C}, \\
\text { vitamin } \mathrm{D}, \mathrm{Zn}\end{array}$ \\
\hline Slovakia & Vitamin C protective plasma value ${ }^{(81)}$ & 2007 & $\begin{array}{l}\text { Males and females } \\
\text { aged } 19-68 \text { years }\end{array}$ & $\begin{array}{l}78 \mathrm{M} \\
109 \mathrm{~F}\end{array}$ & FFQ & Vitamin C \\
\hline $\begin{array}{c}\text { The Republic } \\
\text { of Srpska }\end{array}$ & The Republic of Srpska lodine Deficiency Survey $2006^{(82)}$ & 2008 & $\begin{array}{l}\text { Boys and girls aged } \\
7-10 \text { years }\end{array}$ & $\begin{array}{l}599 \mathrm{M} \\
592 \mathrm{~F}\end{array}$ & Urinary iodine & lodine \\
\hline
\end{tabular}

M, males; F, females; 24hR, $24 \mathrm{~h}$ recall; 3dDR, $3 \mathrm{~d}$ diet record; HFCS, household food consumption survey.

*For all studies: supplements are not included in the assessment.

tGrey literature. 


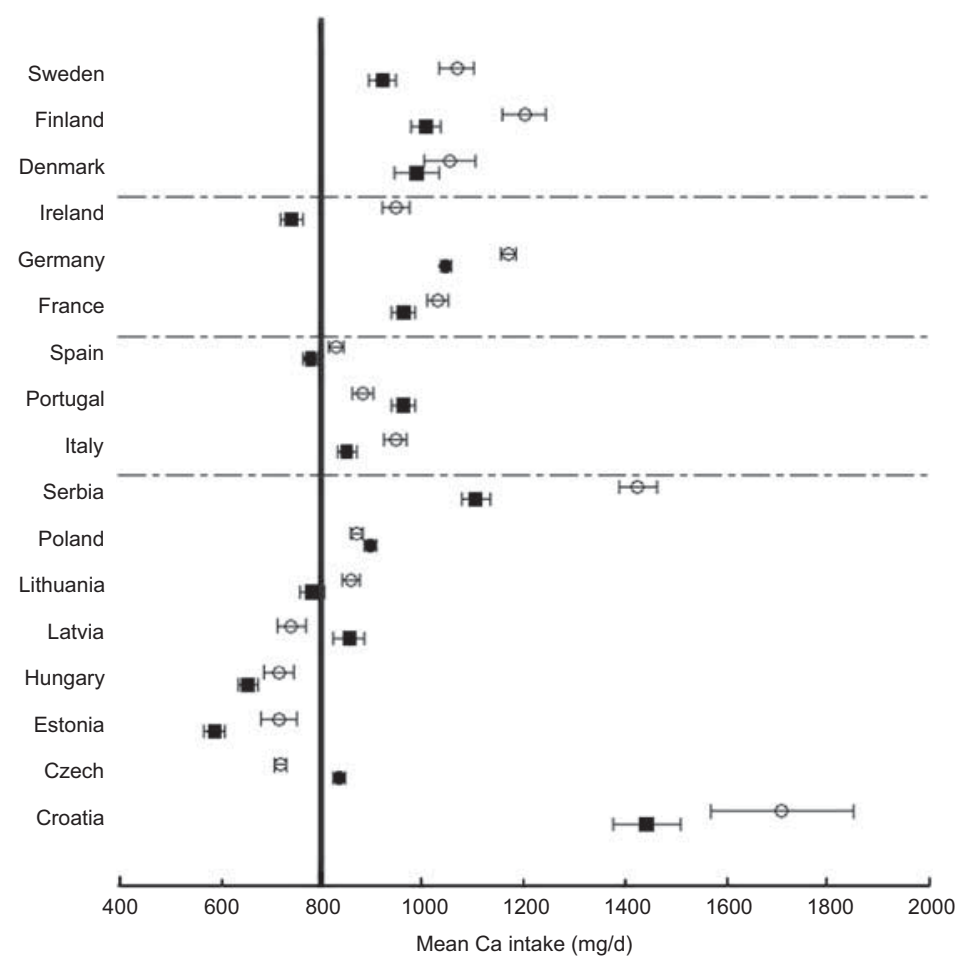

\begin{tabular}{|c|c|c|c|c|c|c|c|}
\hline Country & $\begin{array}{l}\text { Dietary } \\
\text { intake } \\
\text { method }\end{array}$ & $\begin{array}{l}\text { No. of } \\
\text { subjects; } \\
\text { sex }\end{array}$ & $\begin{array}{l}\text { Age } \\
\text { range } \\
\text { (years) }\end{array}$ & $\begin{array}{l}\text { Mean } \\
(\mathrm{mg} / \mathrm{d})\end{array}$ & SD & $\begin{array}{l}\text { Energy } \\
(\mathrm{kJ} / \mathrm{d})\end{array}$ & SD \\
\hline Sweden ${ }^{(16)}$ & EFR & $\begin{array}{l}500 \mathrm{M} \\
500 \mathrm{~F}\end{array}$ & 19-64 & $\begin{array}{l}1069 \\
922\end{array}$ & $\begin{array}{l}395 \\
300\end{array}$ & $\begin{array}{l}9933 \\
7841\end{array}$ & \\
\hline Finland $d^{(16)}$ & $24 \mathrm{hR}$ & $\begin{array}{l}730 \mathrm{M} \\
846 \mathrm{~F}\end{array}$ & $19-64$ & $\begin{array}{l}1202 \\
1007\end{array}$ & $\begin{array}{l}592 \\
450\end{array}$ & $\begin{array}{l}9265 \\
6804\end{array}$ & $\begin{array}{l}2960 \\
2028\end{array}$ \\
\hline Denmark ${ }^{(16)}$ & EFR & $\begin{array}{l}300 \mathrm{M} \\
300 \mathrm{~F}\end{array}$ & $19-64$ & $\begin{array}{l}1055 \\
990 \\
\end{array}$ & $\begin{array}{r}448 \\
389 \\
\end{array}$ & $\begin{array}{l}10638 \\
8232 \\
\end{array}$ & $\begin{array}{r}2910 \\
2209 \\
\end{array}$ \\
\hline Ireland ${ }^{(16)}$ & EFR & $\begin{array}{l}650 \mathrm{M} \\
650 \mathrm{~F}\end{array}$ & $19-64$ & $\begin{array}{l}949 \\
742\end{array}$ & $\begin{array}{l}354 \\
299\end{array}$ & $\begin{array}{l}11033 \\
7623\end{array}$ & $\begin{array}{l}3108 \\
2007\end{array}$ \\
\hline Germany ${ }^{(16)}$ & DH & $\begin{array}{l}5000 \mathrm{M} \\
5000 \mathrm{~F}\end{array}$ & $19-64$ & $\begin{array}{l}1171 \\
1047\end{array}$ & $\begin{array}{l}558 \\
389\end{array}$ & $\begin{array}{l}11041 \\
8131\end{array}$ & $\begin{array}{l}4112 \\
2511\end{array}$ \\
\hline France ${ }^{(16)}$ & EFR & $\begin{array}{l}954 \mathrm{M} \\
800 \mathrm{~F}\end{array}$ & $52-68$ & $\begin{array}{l}1032 \\
964 \\
\end{array}$ & $\begin{array}{r}325 \\
339 \\
\end{array}$ & NA & \\
\hline$\overline{\text { Spain }^{(16)}}$ & $2 \times 24 \overline{h R}$ & $\begin{array}{l}750 \mathrm{M} \\
750 \mathrm{~F}\end{array}$ & $\overline{19-59}$ & $\begin{array}{l}830 \\
778\end{array}$ & $\begin{array}{l}200 \\
170\end{array}$ & $\begin{array}{l}8925 \\
7047\end{array}$ & \\
\hline Portugal ${ }^{(16)}$ & FFQ & $\begin{array}{l}1200 \mathrm{M} \\
1200 \mathrm{~F}\end{array}$ & $19-64$ & $\begin{array}{l}883 \\
963\end{array}$ & $\begin{array}{l}354 \\
359\end{array}$ & $\begin{array}{l}9937 \\
8731\end{array}$ & $\begin{array}{l}2305 \\
2108\end{array}$ \\
\hline Italy ${ }^{(16)}$ & EFR & $\begin{array}{l}700 \mathrm{M} \\
700 \mathrm{~F} \\
\end{array}$ & $19-64$ & $\begin{array}{l}947 \\
851 \\
\end{array}$ & $\begin{array}{r}309 \\
-264 \\
\end{array}$ & $\begin{array}{l}10336 \\
8433 \\
\end{array}$ & $\begin{array}{r}1906 \\
1604 \\
\end{array}$ \\
\hline Serbia ${ }^{(36)}$ & HFCS & $\begin{array}{l}1173 \mathrm{M} \\
1227 \mathrm{~F}\end{array}$ & $30-60$ & $\begin{array}{l}1426 \\
1105\end{array}$ & $\begin{array}{l}643 \\
501\end{array}$ & 11415 (M\& & \\
\hline Poland $d^{(56)}$ & $\mathrm{FFQ}$ & $\begin{array}{l}4815 \mathrm{M} \\
5044 \mathrm{~F}\end{array}$ & $45-69$ & $\begin{array}{l}872 \\
899\end{array}$ & $\begin{array}{l}425 \\
438\end{array}$ & $\begin{array}{l}9529 \\
8727\end{array}$ & $\begin{array}{l}2910 \\
2608\end{array}$ \\
\hline Lithuania $^{(66)}$ & $24 \mathrm{hR}$ & $\begin{array}{l}2606 \mathrm{M} \\
1132 \mathrm{~F}\end{array}$ & $19-64$ & $\begin{array}{l}858 \\
782\end{array}$ & $\begin{array}{l}468 \\
420\end{array}$ & $\begin{array}{l}10945 \\
8202\end{array}$ & $\begin{array}{l}4317 \\
3494\end{array}$ \\
\hline Latvia $^{(66)}$ & $24 \mathrm{hR}$ & $\begin{array}{l}1065 \mathrm{M} \\
1235 \mathrm{~F}\end{array}$ & $19-64$ & $\begin{array}{l}742 \\
855\end{array}$ & $\begin{array}{l}456 \\
547\end{array}$ & $\begin{array}{l}10848 \\
7522\end{array}$ & $\begin{array}{l}5023 \\
3355\end{array}$ \\
\hline Hungary ${ }^{(69)}$ & $24 \mathrm{hR}$ & $\begin{array}{l}473 \mathrm{M} \\
706 \mathrm{~F}\end{array}$ & $18-60+$ & $\begin{array}{l}717 \\
656\end{array}$ & $\begin{array}{l}319 \\
276\end{array}$ & $\begin{array}{l}11734 \\
9227\end{array}$ & \\
\hline Estonia $^{(6)}$ & $24 \mathrm{hR}$ & $\begin{array}{l}900 \mathrm{M} \\
115 \mathrm{~F}\end{array}$ & $19-64$ & $\begin{array}{l}716 \\
589\end{array}$ & $\begin{array}{l}544 \\
362\end{array}$ & $\begin{array}{l}9567 \\
6888\end{array}$ & $\begin{array}{l}4804 \\
3217\end{array}$ \\
\hline $\begin{array}{l}\text { Czech } \\
\text { Republic }^{(57)}\end{array}$ & $\mathrm{FFQ}$ & $\begin{array}{l}3690 \mathrm{M} \\
4223 \mathrm{~F}\end{array}$ & $51-65$ & $\begin{array}{l}721 \\
835\end{array}$ & $\begin{array}{l}362 \\
411\end{array}$ & $\begin{array}{l}8727 \\
4867\end{array}$ & $\begin{array}{l}3007 \\
3007\end{array}$ \\
\hline Croatia $^{(52)}$ & $\mathrm{FFQ}$ & $\begin{array}{l}183 \mathrm{M} \\
480 \mathrm{~F}\end{array}$ & $18-30$ & $\begin{array}{l}1711 \\
1444\end{array}$ & $\begin{array}{l}965 \\
740\end{array}$ & $\begin{array}{l}15955 \\
11982\end{array}$ & $\begin{array}{l}7534 \\
5720\end{array}$ \\
\hline
\end{tabular}

Fig. 1 Mean (SD) calcium intake in $\mathrm{mg} / \mathrm{d}$ and mean (SD) energy intake in $\mathrm{kJ} / \mathrm{d}$ for males $(\mathrm{M})$ and females $(\mathrm{F})$ by country and region (separated at - - - from top to bottom, into Scandinavia, Western Europe, Mediterranean and Central and Eastern Europe). Dietary intake method: EFR = estimated food record; $24 \mathrm{hR}=24 \mathrm{~h}$ recall; $\mathrm{DH}=$ diet history; HFCS $=$ household food consumption survey. NA = not available. Plot shows mean intakes with $95 \%$ confidence intervals represented by horizontal bars: $\bigcirc$, males; females; — - Average Nutrient Requirement $(800 \mathrm{mg} / \mathrm{d}$ for females and males)

females in Estonia, Hungary and Lithuania was below the ANR (source: NNR), which indicates that there is a risk of inadequacy. Similar results were observed for CEE males (pooled estimated mean: $862 \mathrm{mg} / \mathrm{d}$ ); the pooled mean Ca intakes for Scandinavian, Western European and Mediterranean countries were 1130, 1129 and $885 \mathrm{mg} / \mathrm{d}$, respectively. In CEE, four out of eight countries had a mean intake below the ANR among males, and in three countries among females. Within CEE, relatively high levels of $\mathrm{Ca}$ intake were observed for Croatia and Serbia. This can likely be explained by the different age range of the study population in the Croatian study (university students, 18-30 years) and the different dietary assessment method used in the Serbian study (intake data were collected per household and calculated per person using the consumption units). This explanation is supported by the fact that mean energy intakes in these studies are also relatively high. This remark also holds for the levels of intake of other micronutrients from these two studies.

Figure 2 shows the observed mean intakes for folate. In CEE the mean pooled intake $(307 \mu \mathrm{g} / \mathrm{d})$ was slightly higher than in the other regions (Scandinavia: $235 \mu \mathrm{g} / \mathrm{d}$, Western Europe: $278 \mu \mathrm{g} / \mathrm{d}$, Mediterranean: $275 \mu \mathrm{g} / \mathrm{d}$ ), which was due to the relatively high value for Croatia. In CEE, Hungarian and Estonian females had mean intake below the ANR, indicating a risk of inadequacy. Among CEE males, the estimated mean intake $(302 \mu \mathrm{g} / \mathrm{d})$ was in the same range as those in other regions (Scandinavia: $268 \mu \mathrm{g} / \mathrm{d}$, Western Europe: $322 \mu \mathrm{g} / \mathrm{d}$, Mediterranean: $287 \mu \mathrm{g} / \mathrm{d}$ ). Hungarian males had folate intake below the ANR.

These results correspond with the previous publication by de Bree et $a l .^{(34)}$ which indicated that mean dietary folate intake in Europe is in line with recommendations.

The observed mean Fe intakes are shown in Fig. 3. The pooled mean intake among females from CEE $(13 \mathrm{mg} / \mathrm{d})$ was similar to those from the other European regions (range: $11-13 \mathrm{mg} / \mathrm{d}$ ). For all CEE countries the mean intake of females was above the ANR with the exception of Hungary. For males, the mean estimated intake in CEE $(16 \mathrm{mg} / \mathrm{d})$ was slightly higher than that in other regions (range: $13-15 \mathrm{mg} / \mathrm{d}$ ); all countries reported an observed mean intake higher than the average daily requirements.

The mean intakes of vitamin $\mathrm{B}_{12}$ are shown in Fig. 4. The pooled levels for both females and males in CEE ( 4 and $7 \mu \mathrm{g} / \mathrm{d}$, respectively) were similar to the pooled means for Scandinavia and Western Europe, whereas the highest means were observed in the Mediterranean countries $(7 \mu \mathrm{g} / \mathrm{d}$ in females, $8 \mu \mathrm{g} / \mathrm{d}$ in males). For both genders in all countries, mean intake values were above the ANR.

The mean observed vitamin $\mathrm{C}$ intake (Fig. 5) in CEE females (pooled estimate: $134 \mathrm{mg} / \mathrm{d}$ ) was similar to that in 


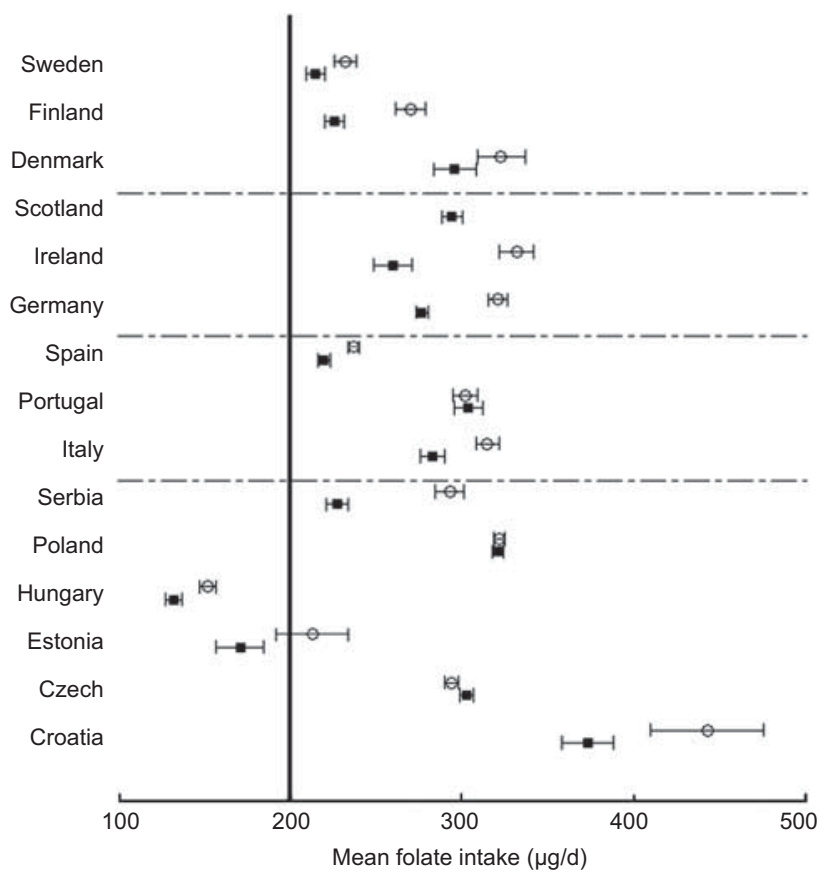

\begin{tabular}{|c|c|c|c|c|c|c|c|}
\hline Country & $\begin{array}{l}\text { Dietary } \\
\text { intake } \\
\text { method }\end{array}$ & $\begin{array}{l}\text { No. of } \\
\text { subjects; } \\
\text { sex }\end{array}$ & $\begin{array}{l}\text { Age } \\
\text { range } \\
\text { (years) }\end{array}$ & $\begin{array}{l}\text { Mean } \\
(\mu \mathrm{g} / \mathrm{d})\end{array}$ & SD & $\begin{array}{l}\text { Energy } \\
(\mathrm{kJ} / \mathrm{d})\end{array}$ & SD \\
\hline Sweden $(16)$ & EFR & $\begin{array}{l}500 \mathrm{M} \\
500 \mathrm{~F}\end{array}$ & $19-64$ & $\begin{array}{l}232 \\
215\end{array}$ & $\begin{array}{l}73 \\
65\end{array}$ & $\begin{array}{l}9933 \\
7841\end{array}$ & \\
\hline Finland ${ }^{(16)}$ & $24 \mathrm{hR}$ & $\begin{array}{l}730 \mathrm{M} \\
846 \mathrm{~F}\end{array}$ & $19-64$ & $\begin{array}{l}270 \\
226\end{array}$ & $\begin{array}{l}120 \\
88\end{array}$ & $\begin{array}{l}9265 \\
6804\end{array}$ & $\begin{array}{l}2960 \\
2028\end{array}$ \\
\hline $\operatorname{Denmark}^{(16)}$ & EFR & $\begin{array}{l}300 \mathrm{M} \\
300 \mathrm{~F} \\
\end{array}$ & $19-64$ & $\begin{array}{r}323 \\
-296 \\
\end{array}$ & $\begin{array}{l}120 \\
111 \\
\end{array}$ & $\begin{array}{l}10638 \\
8232 \\
-\end{array}$ & $\begin{array}{r}2910 \\
-2209 \\
\end{array}$ \\
\hline Scotland $\overline{(16)}-$ & $\overline{F F Q}$ & $898 \mathrm{~F}$ & $45-54$ & 294 & 89 & 7925 & \\
\hline $\begin{array}{l}\text { Ireland }^{(16)} \\
\text { Germany }^{(16)}\end{array}$ & EFR & $\begin{array}{l}650 \mathrm{M} \\
650 \mathrm{~F} \\
5000 \mathrm{M} \\
5000 \mathrm{~F}\end{array}$ & $19-64$ & $\begin{array}{l}332 \\
260 \\
321 \\
277\end{array}$ & $\begin{array}{l}128 \\
144 \\
202 \\
124\end{array}$ & $\begin{array}{l}11033 \\
7623 \\
11041 \\
8131\end{array}$ & $\begin{array}{l}3108 \\
2007 \\
4112 \\
2511\end{array}$ \\
\hline$\overline{\text { Spain }} \overline{(16)}$ & $2 \times \overline{24 h} \bar{R}$ & $\begin{array}{l}\overline{750} \overline{\mathrm{M}} \\
750 \mathrm{~F}\end{array}$ & $\overline{1} \overline{9} \overline{-59}-$ & $\begin{array}{l}2 \overline{3} 7 \\
220\end{array}$ & $\begin{array}{l}45 \\
48\end{array}$ & $\begin{array}{l}\overline{89} 25 \\
7047\end{array}$ & \\
\hline Portugal ${ }^{(16)}$ & $\mathrm{FFQ}$ & $\begin{array}{l}1200 \mathrm{M} \\
1200 \mathrm{~F}\end{array}$ & $19-64$ & $\begin{array}{l}302 \\
304\end{array}$ & $\begin{array}{l}130 \\
144\end{array}$ & $\begin{array}{l}9937 \\
8731\end{array}$ & $\begin{array}{l}2305 \\
2108\end{array}$ \\
\hline Italy(16) & EFR & $\begin{array}{l}700 \mathrm{M} \\
700 \mathrm{~F} \\
\end{array}$ & $19-64$ & $\begin{array}{r}315 \\
-283 \\
-\end{array}$ & $\begin{array}{l}91 \\
100 \\
\end{array}$ & $\begin{array}{l}10336 \\
8433 \\
-\end{array}$ & $\begin{array}{r}1906 \\
-1604 \\
\end{array}$ \\
\hline Serbia ${ }^{(36)}$ & HFCS & $\begin{array}{l}1173 \mathrm{M} \\
1227 \mathrm{~F}\end{array}$ & $30-60$ & $\begin{array}{l}293 \\
228\end{array}$ & $\begin{array}{l}148 \\
116\end{array}$ & \multicolumn{2}{|c|}{11415 (M\&F) } \\
\hline Poland ${ }^{(56)}$ & FFQ & $\begin{array}{l}4815 \mathrm{M} \\
5044 \mathrm{~F}\end{array}$ & $45-69$ & $\begin{array}{l}322 \\
321\end{array}$ & $\begin{array}{l}118 \\
124\end{array}$ & $\begin{array}{l}9529 \\
8727\end{array}$ & $\begin{array}{l}2910 \\
2608\end{array}$ \\
\hline $\begin{array}{l}\text { Hungary }{ }^{(69)} \\
\text { Hungary }\end{array}$ & $\begin{array}{l}24 \mathrm{hR} \\
3 \times 24 \mathrm{hR}\end{array}$ & $\begin{array}{l}473 \mathrm{M} \\
352 \mathrm{~F}\end{array}$ & $\begin{array}{l}18-60+ \\
18-59\end{array}$ & $\begin{array}{l}152 \\
132\end{array}$ & $\begin{array}{l}53 \\
47\end{array}$ & $\begin{array}{l}11734 \\
9227\end{array}$ & \\
\hline $\begin{array}{l}\text { Estonia(50) } \\
\text { Czech } \\
\text { Republic }^{(57)}\end{array}$ & $\begin{array}{l}24 \mathrm{hR} \\
\mathrm{FFQ}\end{array}$ & $\begin{array}{l}126 \mathrm{M} \\
190 \mathrm{~F} \\
3690 \mathrm{M} \\
4223 \mathrm{~F}\end{array}$ & $\begin{array}{l}55-65 \\
51-65\end{array}$ & $\begin{array}{l}213 \\
171 \\
294 \\
303\end{array}$ & $\begin{array}{l}121 \\
99 \\
115 \\
135\end{array}$ & $\begin{array}{l}9567 \\
6888 \\
8727 \\
4867\end{array}$ & $\begin{array}{l}4804 \\
3217 \\
3007 \\
3007\end{array}$ \\
\hline Croatia $^{(52)}$ & FFQ & $\begin{array}{l}183 \mathrm{M} \\
480 \mathrm{~F}\end{array}$ & $18-30$ & $\begin{array}{l}443 \\
373\end{array}$ & $\begin{array}{l}226 \\
168\end{array}$ & $\begin{array}{l}15955 \\
11982\end{array}$ & $\begin{array}{l}7534 \\
5720\end{array}$ \\
\hline
\end{tabular}

Fig. 2 Mean (SD) folate intake in $\mu \mathrm{g} / \mathrm{d}$ and mean (SD) energy intake in $\mathrm{kJ} / \mathrm{d}$ for males (M) and females (F) by country and region (separated at - - - , from top to bottom, into Scandinavia, Western Europe, Mediterranean and Central and Eastern Europe). Dietary intake method: EFR = estimated food record; $24 \mathrm{hR}=24 \mathrm{~h}$ recall; $\mathrm{DH}=$ diet history; HFCS $=$ household food consumption survey. NA = not available. Plot shows mean intakes with $95 \%$ confidence intervals represented by horizontal bars: $\bigcirc$, males; $\square$ females; - - Average Nutrient Requirement $(200 \mu \mathrm{g} / \mathrm{d}$ for females and males)

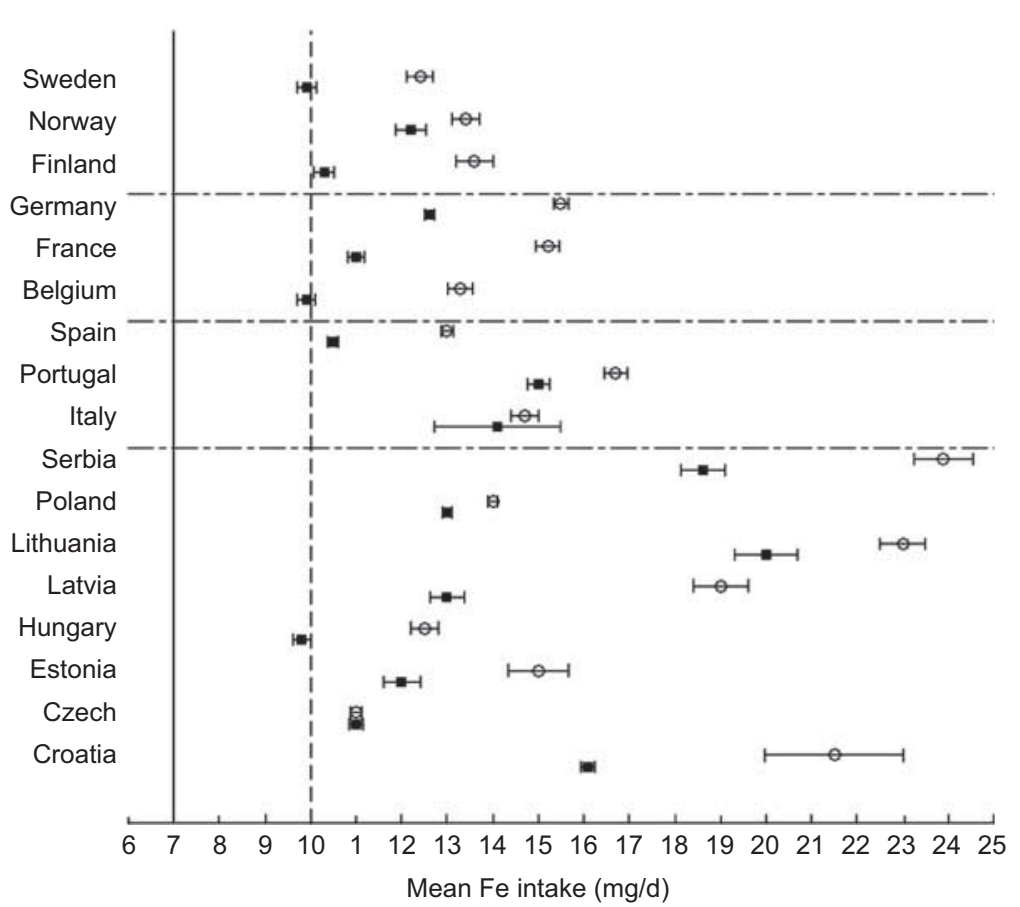

\begin{tabular}{|c|c|c|c|c|c|c|c|}
\hline Country & $\begin{array}{l}\text { Dietary } \\
\text { intake } \\
\text { method }\end{array}$ & $\begin{array}{l}\text { No. of } \\
\text { subjects; } \\
\text { sex }\end{array}$ & $\begin{array}{l}\text { Age } \\
\text { range } \\
\text { (years) }\end{array}$ & $\begin{array}{l}\text { Mean } \\
(\mathrm{mg} / \mathrm{d})\end{array}$ & SD & $\begin{array}{l}\text { Energy } \\
(\mathrm{kJ} / \mathrm{d})\end{array}$ & SD \\
\hline Sweden $^{(16)}$ & EFR & $\begin{array}{l}500 \mathrm{M} \\
500 \mathrm{~F}\end{array}$ & $19-64$ & $\begin{array}{l}12 \\
10\end{array}$ & $\begin{array}{l}3 \\
2\end{array}$ & $\begin{array}{l}9933 \\
7841\end{array}$ & \\
\hline Norway ${ }^{(16)}$ & FFQ & $\begin{array}{l}1100 \mathrm{M} \\
1100 \mathrm{~F}\end{array}$ & $16-79$ & $\begin{array}{l}13 \\
12\end{array}$ & $\begin{array}{l}5 \\
6\end{array}$ & $\begin{array}{l}11142 \\
1936\end{array}$ & $\begin{array}{l}3914 \\
645\end{array}$ \\
\hline Finland $^{(16)}$ & $24 \mathrm{hR}$ & $\begin{array}{l}730 \mathrm{M} \\
846 \mathrm{~F} \\
\end{array}$ & $19-64$ & $\begin{array}{l}14 \\
10 \\
\end{array}$ & $\begin{array}{l}6 \\
3 \\
\end{array}$ & $\begin{array}{l}9265 \\
6804 \\
\end{array}$ & $\begin{array}{l}2960 \\
2028 \\
\end{array}$ \\
\hline Germany $^{(16)}$ & $\mathrm{DH}$ & $\begin{array}{l}5000 \mathrm{M} \\
5000 \mathrm{~F}\end{array}$ & $19-64$ & $\begin{array}{l}16 \\
13\end{array}$ & $\begin{array}{l}6 \\
4\end{array}$ & $\begin{array}{l}11041 \\
8131\end{array}$ & $\begin{array}{l}4112 \\
2511\end{array}$ \\
\hline France $^{(16)}$ & EFR & $\begin{array}{l}954 \mathrm{M} \\
800 \mathrm{~F}\end{array}$ & $52-68$ & $\begin{array}{l}15 \\
11\end{array}$ & $\begin{array}{l}4 \\
3\end{array}$ & NA & \\
\hline Belgium $^{(16)}$ & $24 \mathrm{hR}$ & $\begin{array}{l}500 \mathrm{M} \\
500 \mathrm{~F} \\
\end{array}$ & $19-64$ & $\begin{array}{l}13 \\
10 \\
\end{array}$ & $\begin{array}{l}3 \\
2 \\
\end{array}$ & NA & \\
\hline$\overline{S p a i n}^{\sqrt{116}}$ & $2 \times 24 \mathrm{hR}$ & $\begin{array}{l}750 \overline{\mathrm{M}} \\
750 \mathrm{~F}\end{array}$ & $19-59$ & $\begin{array}{l}13- \\
11\end{array}$ & $\begin{array}{l}2 \\
2\end{array}$ & $\begin{array}{l}8925 \\
7047\end{array}$ & \\
\hline Portugal ${ }^{(16)}$ & FFQ & $\begin{array}{l}1200 \mathrm{M} \\
1200 \mathrm{~F}\end{array}$ & $19-64$ & $\begin{array}{l}17 \\
15\end{array}$ & $\begin{array}{l}5 \\
4\end{array}$ & $\begin{array}{l}9937 \\
8731\end{array}$ & $\begin{array}{l}2305 \\
2108\end{array}$ \\
\hline Italy ${ }^{(16)}$ & EFR & $\begin{array}{l}700 \mathrm{M} \\
700 \mathrm{~F}\end{array}$ & $19-64$ & $\begin{array}{l}15 \\
14 \\
\end{array}$ & $\begin{array}{l}4 \\
19 \\
\end{array}$ & $\begin{array}{l}10336 \\
8433 \\
\end{array}$ & $\begin{array}{r}1906 \\
1604 \\
\end{array}$ \\
\hline Serbia ${ }^{(36)}$ & $\mathrm{HFCS}$ & $\begin{array}{l}1173 \mathrm{M} \\
1227 \mathrm{~F}\end{array}$ & $30-60$ & $\begin{array}{l}24 \\
19\end{array}$ & $\begin{array}{l}11 \\
9\end{array}$ & 11415 (M\&F) & \\
\hline Poland ${ }^{(56)}$ & FFQ & $\begin{array}{l}4815 \mathrm{M} \\
5044 \mathrm{~F}\end{array}$ & $45-69$ & $\begin{array}{l}14 \\
13\end{array}$ & $\begin{array}{l}4 \\
4\end{array}$ & $\begin{array}{l}9529 \\
8727\end{array}$ & $\begin{array}{l}2910 \\
2608\end{array}$ \\
\hline Lithuania $^{(66)}$ & $24 \mathrm{hR}$ & $\begin{array}{l}2606 \mathrm{M} \\
1132 \mathrm{~F}\end{array}$ & $19-64$ & $\begin{array}{l}23 \\
20\end{array}$ & $\begin{array}{l}13 \\
12\end{array}$ & $\begin{array}{l}10945 \\
8202\end{array}$ & $\begin{array}{l}4317 \\
3494\end{array}$ \\
\hline Latvia ${ }^{66)}$ & $24 \mathrm{hR}$ & $\begin{array}{l}1065 \mathrm{M} \\
1235 \mathrm{~F}\end{array}$ & $19-64$ & $\begin{array}{l}19 \\
13\end{array}$ & $\begin{array}{l}10 \\
7\end{array}$ & $\begin{array}{l}10848 \\
7522\end{array}$ & $\begin{array}{l}5023 \\
3355\end{array}$ \\
\hline Hungary ${ }^{(69)}$ & $24 \mathrm{hR}$ & $\begin{array}{l}473 \mathrm{M} \\
706 \mathrm{~F}\end{array}$ & $18-60+$ & $\begin{array}{l}13 \\
10\end{array}$ & $\begin{array}{l}3 \\
3\end{array}$ & $\begin{array}{l}11734 \\
9227\end{array}$ & \\
\hline Estonia $^{(66)}$ & $24 \mathrm{hR}$ & $\begin{array}{l}900 \mathrm{M} \\
1115 \mathrm{~F}\end{array}$ & $19-64$ & $\begin{array}{l}15 \\
12\end{array}$ & $\begin{array}{l}10 \\
7\end{array}$ & $\begin{array}{l}9567 \\
6888\end{array}$ & $\begin{array}{l}4804 \\
3217\end{array}$ \\
\hline $\begin{array}{l}\text { Czech } \\
\text { Republic }\end{array}$ & FFQ & $\begin{array}{l}3690 \mathrm{M} \\
4223 \mathrm{~F}\end{array}$ & $51-65$ & $\begin{array}{l}11 \\
11\end{array}$ & $\begin{array}{l}4 \\
5\end{array}$ & $\begin{array}{l}8727 \\
4867\end{array}$ & $\begin{array}{l}3007 \\
3007\end{array}$ \\
\hline Croatia $^{(52)}$ & FFQ & $\begin{array}{l}183 \mathrm{M} \\
480 \mathrm{~F}\end{array}$ & $18-30$ & $\begin{array}{l}22 \\
16\end{array}$ & $\begin{array}{l}10 \\
2\end{array}$ & $\begin{array}{l}15955 \\
11982\end{array}$ & $\begin{array}{l}7534 \\
5720\end{array}$ \\
\hline
\end{tabular}

Fig. 3 Mean (SD) iron intake in $\mathrm{mg} / \mathrm{d}$ and mean (SD) energy intake in $\mathrm{kJ} / \mathrm{d}$ for males (M) and females (F) by country and region (separated at - - - from top to bottom, into Scandinavia, Western Europe, Mediterranean and Central and Eastern Europe). Dietary intake method: EFR = estimated food record; $24 \mathrm{hR}=24 \mathrm{~h}$ recall; $\mathrm{DH}=$ diet history; HFCS $=$ household food consumption survey. $\mathrm{NA}=$ not available. Plot shows mean intakes with $95 \%$ confidence intervals represented by horizontal bars: $\bigcirc$, males; females; —_ Average Nutrient Requirement (ANR; $7 \mathrm{mg} / \mathrm{d}$ for males); - - -, ANR (10 mg/d for females) 


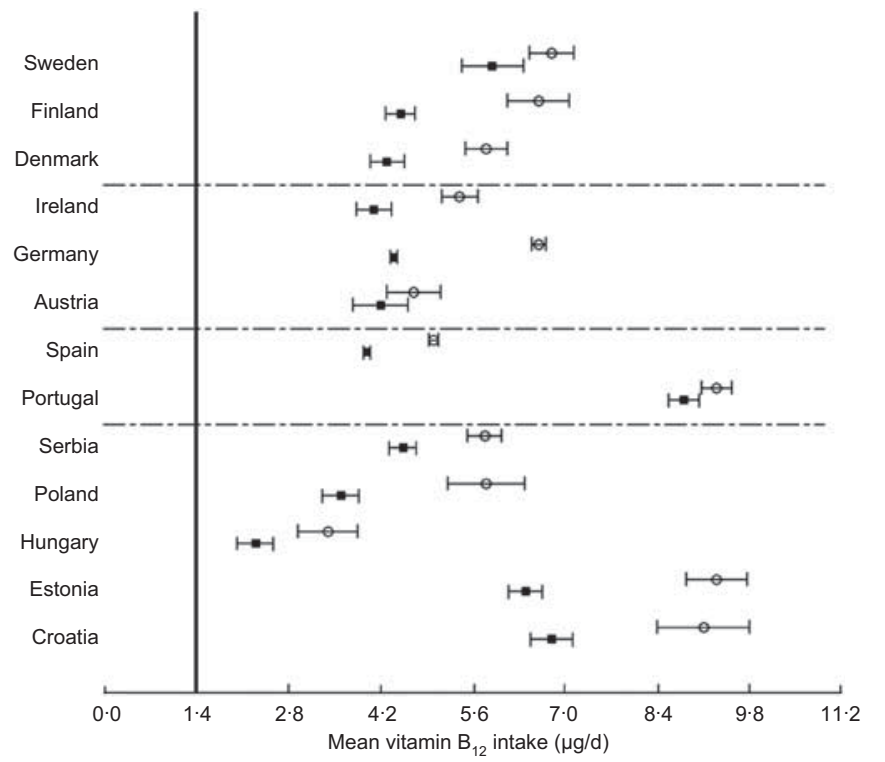

\begin{tabular}{|c|c|c|c|c|c|c|c|}
\hline Country & $\begin{array}{l}\text { Dietary } \\
\text { intake } \\
\text { method }\end{array}$ & $\begin{array}{l}\text { No. of } \\
\text { subjects; } \\
\text { sex }\end{array}$ & $\begin{array}{l}\begin{array}{l}\text { Age range } \\
\text { (years) }\end{array} \\
\end{array}$ & $\begin{array}{l}\text { Mean } \\
(\mathrm{mg} / \mathrm{d})\end{array}$ & SD & $\begin{array}{l}\text { Energy } \\
(\mathrm{kJ} / \mathrm{d})\end{array}$ & SD \\
\hline \multirow[t]{2}{*}{ Sweden ${ }^{(16)}$} & EFR & $500 \mathrm{M}$ & $19-64$ & 7 & 4 & 9933 & \\
\hline & & $500 \mathrm{~F}$ & & 6 & 5 & 7841 & \\
\hline \multirow[t]{2}{*}{ Finland ${ }^{(16)}$} & $24 \mathrm{hR}$ & $730 \mathrm{M}$ & $19-64$ & 7 & 6 & 9265 & 2960 \\
\hline & & $846 \mathrm{~F}$ & & 5 & 3 & 6804 & 2028 \\
\hline \multirow[t]{2}{*}{ Denmark $^{(16)}$} & WFR & $400 \mathrm{M}$ & $19-64$ & 6 & 3 & 10638 & 2910 \\
\hline & & $-400 \mathrm{~F}$ & & 4 & 3 & -8232 & -2209 \\
\hline \multirow[t]{2}{*}{ |reland ${ }^{(16)}$} & EFR & $700 \mathrm{M}$ & $19-64$ & 5 & 4 & 11033 & 3108 \\
\hline & & $700 \mathrm{~F}$ & & 4 & 4 & 7623 & 2007 \\
\hline \multirow[t]{2}{*}{ Germany $^{(16)}$} & $\mathrm{DH}$ & $5000 \mathrm{M}$ & $19-64$ & 7 & 4 & 11041 & 4112 \\
\hline & & $5000 \mathrm{~F}$ & & 4 & 2 & 8131 & 2511 \\
\hline \multirow[t]{2}{*}{ Austria $^{(16)}$} & EFR & $125 \mathrm{M}$ & $>64$ & 5 & 2 & 8026 & \\
\hline & & $125 \mathrm{~F}$ & & 4 & 2 & 6921 & \\
\hline \multirow[t]{2}{*}{ Spain } & $2 \times 24 h R$ & $\overline{750} \mathrm{M}$ & $19-59$ & 5 & -1 & 8925 & \\
\hline & & $750 \mathrm{~F}$ & & 4 & 1 & 7047 & \\
\hline \multirow[t]{2}{*}{ Portuga $\left.\right|^{(46)}$} & FFQ & $1200 \mathrm{M}$ & $19-64$ & 9 & 4 & 9937 & 2305 \\
\hline & & $-1200 \mathrm{~F}$ & & 9 & 4 & 8731 & -2108 \\
\hline \multirow[t]{2}{*}{ Serbia $^{(36)}$} & HFCS & $1173 \mathrm{M}$ & $30-60$ & 6 & 4 & 11415 & \\
\hline & & $1227 \mathrm{~F}$ & & 5 & 4 & & \\
\hline \multirow[t]{2}{*}{ Poland $^{(75)}$} & $24 \mathrm{hR}$ & $3132 \mathrm{M}$ & $20-74$ & 6 & 17 & 10386 & \\
\hline & & $3529 \mathrm{~F}$ & & 4 & 8 & 7060 & \\
\hline \multirow[t]{2}{*}{ Hungary ${ }^{(50)}$} & $24 \mathrm{hR}$ & $93 \mathrm{M}$ & $>65$ & 3 & 2 & 10432 & 2205 \\
\hline & & $159 \mathrm{~F}$ & & 2 & 2 & 8828 & 1705 \\
\hline \multirow[t]{2}{*}{ Estonia $^{(50)}$} & $24 \mathrm{hR}$ & $126 \mathrm{M}$ & $55-65$ & 9 & 3 & 9567 & 4804 \\
\hline & & $190 \mathrm{~F}$ & & 6 & 2 & 6888 & 3217 \\
\hline \multirow[t]{2}{*}{ Croatia $^{(52)}$} & FFQ & $183 \mathrm{M}$ & $18-30$ & 9 & 5 & 15955 & 7534 \\
\hline & & $480 \mathrm{~F}$ & & 7 & 4 & 11982 & 5720 \\
\hline
\end{tabular}

Fig. 4 Mean (SD) vitamin $B_{12}$ intake in $\mu \mathrm{g} / \mathrm{d}$ and mean (SD) energy intake in $\mathrm{kJ} / \mathrm{d}$ for males (M) and females $(F)$ by country and region (separated at - - - from top to bottom, into Scandinavia, Western Europe, Mediterranean and Central and Eastern Europe). Dietary intake method: $E F R=$ estimated food record; $24 \mathrm{hR}=24 \mathrm{~h}$ recall; WFR $=$ weighed food record; $\mathrm{DH}=$ diet history; HFCS $=$ household food consumption survey. $\mathrm{NA}=$ not available. Plot shows mean intakes with $95 \%$ confidence intervals represented by horizontal bars: $\bigcirc$, males; $\mathbf{\square}$, females; $\_$. Average Nutrient Requirement $(1.4 \mu \mathrm{g} / \mathrm{d}$ for females and males)

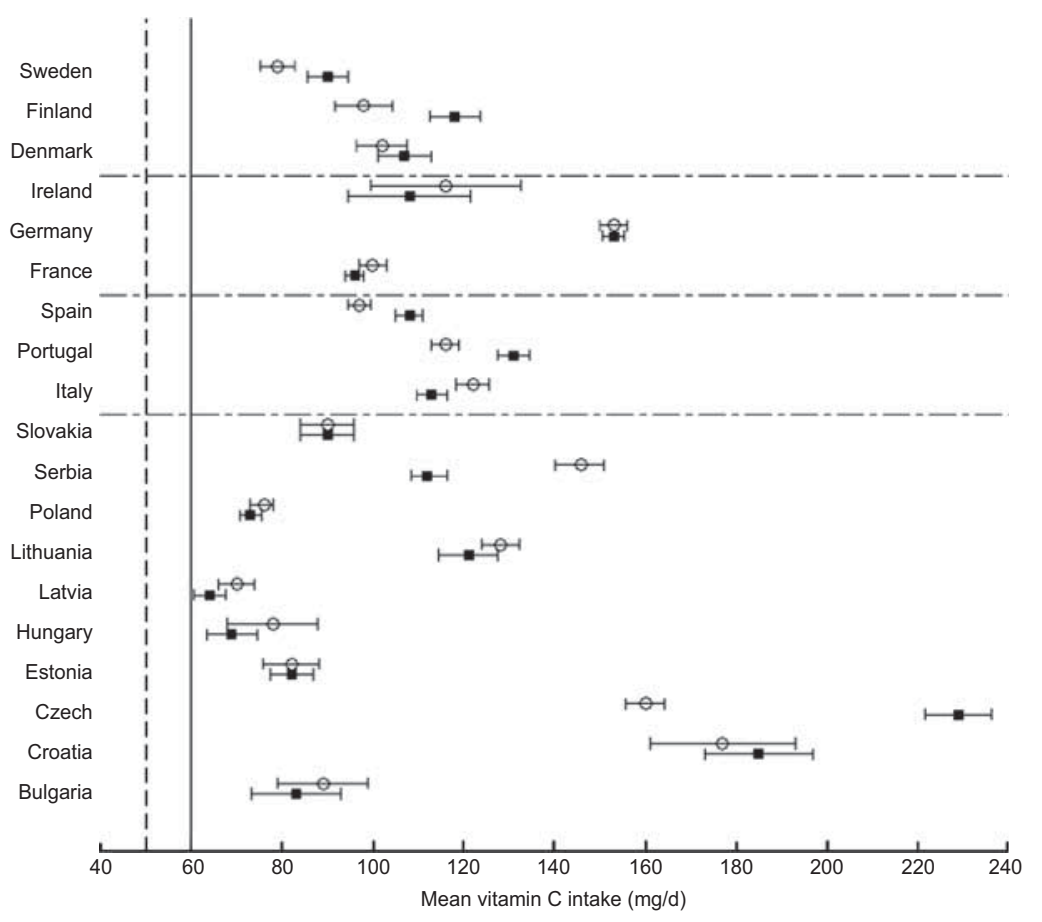

\begin{tabular}{|c|c|c|c|c|c|c|c|}
\hline Country & $\begin{array}{l}\text { Dietary } \\
\text { intake } \\
\text { method }\end{array}$ & $\begin{array}{l}\text { No. of } \\
\text { subjects; } \\
\text { sex }\end{array}$ & $\begin{array}{l}\text { Age } \\
\text { range } \\
\text { (years) }\end{array}$ & $\begin{array}{l}\text { Mean } \\
(\mathrm{mg} / \mathrm{d})\end{array}$ & SD & $\begin{array}{l}\text { Energy } \\
(\mathrm{kJ} / \mathrm{d})\end{array}$ & SD \\
\hline Sweden ${ }^{(16)}$ & EFR & $\begin{array}{l}500 \mathrm{M} \\
500 \mathrm{~F}\end{array}$ & $19-64$ & $\begin{array}{l}79 \\
90\end{array}$ & $\begin{array}{l}45 \\
50\end{array}$ & $\begin{array}{l}9933 \\
7841\end{array}$ & \\
\hline Finland $d^{(16)}$ & $24 \mathrm{hR}$ & $\begin{array}{l}730 \mathrm{M} \\
846 \mathrm{~F}\end{array}$ & $19-64$ & $\begin{array}{l}98 \\
118\end{array}$ & $\begin{array}{l}88 \\
82\end{array}$ & $\begin{array}{l}9265 \\
6804\end{array}$ & $\begin{array}{l}2960 \\
2028\end{array}$ \\
\hline Denmark $^{(16)}$ & WFR & $\begin{array}{l}400 \mathrm{M} \\
400 \mathrm{~F}\end{array}$ & $19-64$ & $\begin{array}{l}102 \\
107 \\
\end{array}$ & $\begin{array}{r}56 \\
61 \\
\end{array}$ & $\begin{array}{l}10638 \\
8232 \\
\end{array}$ & $\begin{array}{r}2910 \\
-2209 \\
\end{array}$ \\
\hline Ireland $\overline{d^{(16)}}$ & EFR & $\begin{array}{l}700 \mathrm{M} \\
700 \mathrm{~F}\end{array}$ & $19-64$ & $\begin{array}{l}\frac{116}{116} \\
108\end{array}$ & $\begin{array}{l}223 \\
183\end{array}$ & $\begin{array}{l}11033 \\
7623\end{array}$ & $\begin{array}{r}-3108 \\
2007\end{array}$ \\
\hline Germany ${ }^{(16)}$ & DH & $\begin{array}{l}5000 \mathrm{M} \\
5000 \mathrm{~F}\end{array}$ & $19-64$ & $\begin{array}{l}153 \\
153\end{array}$ & $\begin{array}{l}106 \\
84\end{array}$ & $\begin{array}{l}11041 \\
8131\end{array}$ & $\begin{array}{l}4112 \\
2511\end{array}$ \\
\hline France $^{(16)}$ & EFR & $\begin{array}{l}954 \mathrm{M} \\
1369 \mathrm{~F}\end{array}$ & $52-68$ & $\begin{array}{l}100 \\
96 \\
\end{array}$ & $\begin{array}{r}49 \\
-43 \\
\end{array}$ & NA & \\
\hline Spain & $2 \times 2 \overline{4 h R}$ & $\begin{array}{l}750 \mathrm{M} \\
750 \mathrm{~F}\end{array}$ & $19-59$ & $\begin{array}{l}830- \\
778\end{array}$ & $\begin{array}{l}200 \\
170\end{array}$ & $\begin{array}{l}8925 \\
7047\end{array}$ & \\
\hline Portuga $f^{(16)}$ & FFQ & $\begin{array}{l}1200 \mathrm{M} \\
1200 \mathrm{~F}\end{array}$ & $19-64$ & $\begin{array}{l}883 \\
963\end{array}$ & $\begin{array}{l}354 \\
359\end{array}$ & $\begin{array}{l}9937 \\
8731\end{array}$ & $\begin{array}{l}2305 \\
2108\end{array}$ \\
\hline Italy ${ }^{(16)}$ & EFR & $\begin{array}{l}700 \mathrm{M} \\
700 \mathrm{~F}\end{array}$ & $19-64$ & $\begin{array}{r}947 \\
851 \\
\end{array}$ & $\begin{array}{r}309 \\
264 \\
\end{array}$ & $\begin{array}{l}10336 \\
8433\end{array}$ & $\begin{array}{r}1906 \\
-1604 \\
\end{array}$ \\
\hline Slovakia ${ }^{807}$ & $\mathrm{FFQ}$ & $\begin{array}{l}68 \mathrm{M} \\
109 \mathrm{~F}\end{array}$ & $19-68$ & $\begin{array}{l}90 \\
90\end{array}$ & & $\overline{N A}$ & \\
\hline Serbia ${ }^{(36)}$ & HFCS & $\begin{array}{l}1173 \mathrm{M} \\
1227 \mathrm{~F}\end{array}$ & $30-60$ & $\begin{array}{l}146 \\
112\end{array}$ & $\begin{array}{l}93 \\
71\end{array}$ & 11415 & 1\&F) \\
\hline Poland ${ }^{(75)}$ & $24 \mathrm{hR}$ & $\begin{array}{l}3132 \mathrm{M} \\
3529 \mathrm{~F}\end{array}$ & $20-74$ & $\begin{array}{l}76 \\
73\end{array}$ & $\begin{array}{l}74 \\
75\end{array}$ & $\begin{array}{l}10386 \\
7060\end{array}$ & \\
\hline Lithuania $^{(66)}$ & $24 \mathrm{hR}$ & $\begin{array}{l}2606 \mathrm{M} \\
1132 \mathrm{~F}\end{array}$ & $19-64$ & $\begin{array}{l}128 \\
121\end{array}$ & $\begin{array}{l}108 \\
112\end{array}$ & $\begin{array}{l}10945 \\
8202\end{array}$ & $\begin{array}{l}4317 \\
3494\end{array}$ \\
\hline Latvia $^{(66)}$ & $24 \mathrm{hR}$ & $\begin{array}{l}1065 \mathrm{M} \\
1235 \mathrm{~F}\end{array}$ & $19-64$ & $\begin{array}{l}70 \\
64\end{array}$ & $\begin{array}{l}65 \\
63\end{array}$ & $\begin{array}{l}10848 \\
7522\end{array}$ & $\begin{array}{l}5023 \\
3355\end{array}$ \\
\hline Hungary ${ }^{(50)}$ & $24 \mathrm{hR}$ & $\begin{array}{l}93 \mathrm{M} \\
159 \mathrm{~F}\end{array}$ & $>65$ & $\begin{array}{l}78 \\
69\end{array}$ & $\begin{array}{l}49 \\
36\end{array}$ & $\begin{array}{l}10432 \\
8828\end{array}$ & $\begin{array}{l}2205 \\
1705\end{array}$ \\
\hline Estonia $^{(66)}$ & $24 \mathrm{hR}$ & $\begin{array}{l}900 \mathrm{M} \\
1115 \mathrm{~F}\end{array}$ & $19-64$ & $\begin{array}{l}82 \\
82\end{array}$ & $\begin{array}{l}96 \\
81\end{array}$ & $\begin{array}{l}9567 \\
6888\end{array}$ & $\begin{array}{l}4804 \\
3217\end{array}$ \\
\hline $\begin{array}{l}\text { Czech } \\
\text { Republic }^{(57)}\end{array}$ & FFQ & $\begin{array}{l}3690 \mathrm{M} \\
4223 \mathrm{~F}\end{array}$ & $51-65$ & $\begin{array}{l}160 \\
229\end{array}$ & $\begin{array}{l}135 \\
242\end{array}$ & $\begin{array}{l}8727 \\
4867\end{array}$ & $\begin{array}{l}3007 \\
3007\end{array}$ \\
\hline Croatia $^{(52)}$ & FFQ & $\begin{array}{l}183 \mathrm{M} \\
480 \mathrm{~F}\end{array}$ & $18-30$ & $\begin{array}{l}177 \\
185\end{array}$ & $\begin{array}{l}111 \\
132\end{array}$ & $\begin{array}{l}15955 \\
11982\end{array}$ & $\begin{array}{l}7534 \\
5720\end{array}$ \\
\hline Bulgaria $^{(50)}$ & $24 \mathrm{~h} \mathrm{R}$ & $\begin{array}{l}186 \mathrm{M} \\
194 \mathrm{~F}\end{array}$ & $60-75$ & $\begin{array}{l}89 \\
83\end{array}$ & $\begin{array}{l}70 \\
70\end{array}$ & $\begin{array}{l}10231 \\
8127\end{array}$ & $\begin{array}{l}4116 \\
2608\end{array}$ \\
\hline
\end{tabular}

Fig. 5 Mean (SD) vitamin $\mathrm{C}$ intake in $\mathrm{mg} / \mathrm{d}$ and mean (SD) energy intake in $\mathrm{kJ} / \mathrm{d}$ for males $(\mathrm{M})$ and females $(\mathrm{F})$ by country and region (separated at - - - from top to bottom, into Scandinavia, Western Europe, Mediterranean and Central and Eastern Europe). Dietary intake method: EFR = estimated food record; $24 \mathrm{hR}=24 \mathrm{~h}$ recall; WFR = weighed food record; $\mathrm{DH}=$ diet history; HFCS $=$ household food consumption survey. NA = not available. Plot shows mean intakes with $95 \%$ confidence intervals represented by horizontal bars: $\bigcirc$, males; $\mathbf{n}$, females; —_ Average Nutrient Requirement (ANR; $60 \mathrm{mg} / \mathrm{d}$ for males); - - -, ANR $(50 \mathrm{mg} / \mathrm{d}$ for females) 


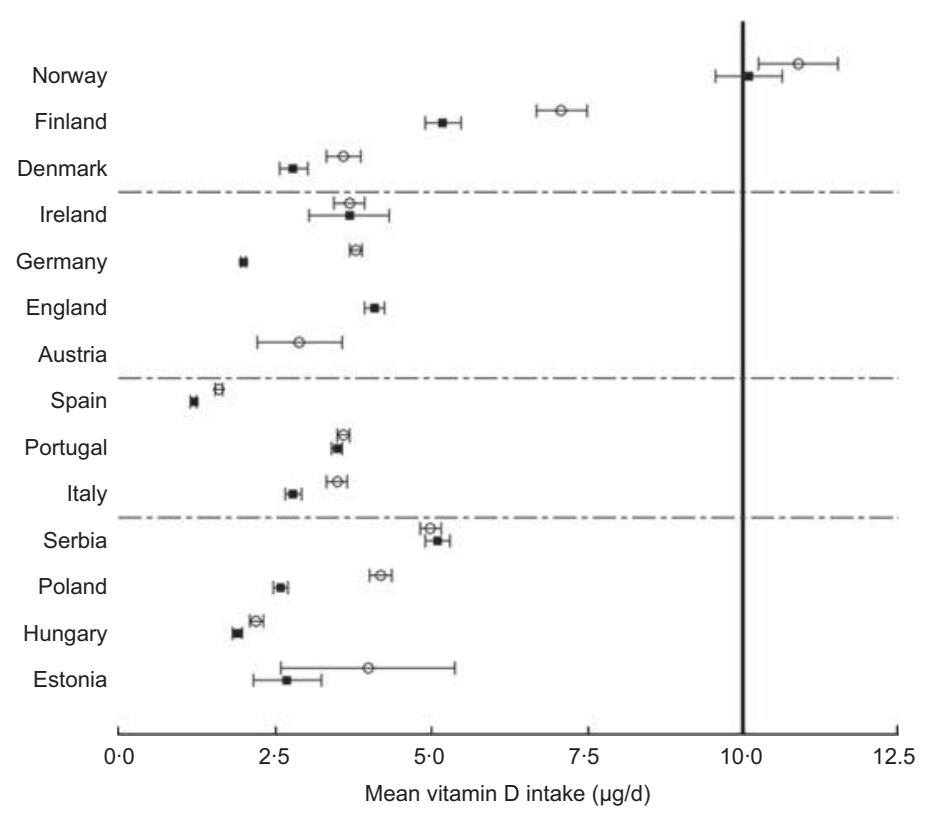

\begin{tabular}{|c|c|c|c|c|c|c|c|}
\hline Country & $\begin{array}{l}\text { Dietary } \\
\text { intake } \\
\text { method }\end{array}$ & $\begin{array}{l}\text { No. of } \\
\text { subjects; } \\
\text { sex }\end{array}$ & $\begin{array}{l}\text { Age } \\
\text { range } \\
\text { (years) }\end{array}$ & $\begin{array}{l}\text { Mean } \\
(\mu \mathrm{g} / \mathrm{d})\end{array}$ & SD & $\begin{array}{l}\text { Energy } \\
(\mathrm{kJ} / \mathrm{d})\end{array}$ & SD \\
\hline Norway $^{(16)}$ & FFQ & $\begin{array}{l}1100 \mathrm{M} \\
1100 \mathrm{~F}\end{array}$ & $16-79$ & $\begin{array}{l}11 \\
10\end{array}$ & $\begin{array}{l}11 \\
9\end{array}$ & $\begin{array}{l}11142 \\
1936\end{array}$ & $\begin{array}{l}3914 \\
645\end{array}$ \\
\hline Finland $^{(16)}$ & $24 \mathrm{~h}$ & $\begin{array}{l}730 \mathrm{M} \\
846 \mathrm{~F}\end{array}$ & $19-64$ & $\begin{array}{l}7 \\
5\end{array}$ & $\begin{array}{l}6 \\
4\end{array}$ & $\begin{array}{l}9265 \\
6804\end{array}$ & $\begin{array}{l}2960 \\
2028\end{array}$ \\
\hline Denmark $^{(16)}$ & WFR & $\begin{array}{l}400 \mathrm{M} \\
400 \mathrm{~F}\end{array}$ & $19-64$ & $\begin{array}{l}4 \\
3 \\
\end{array}$ & $\begin{array}{l}3 \\
2 \\
\end{array}$ & $\begin{array}{l}10638 \\
8232 \\
\end{array}$ & $\begin{array}{r}2910 \\
-2209 \\
\end{array}$ \\
\hline Ireland $^{(16)}$ & EFR & $\begin{array}{l}700 \mathrm{M} \\
700 \mathrm{~F}\end{array}$ & $19-64$ & $\begin{array}{l}4 \\
4\end{array}$ & $\begin{array}{l}3 \\
9\end{array}$ & $\begin{array}{l}11033 \\
7623\end{array}$ & $\begin{array}{l}3108 \\
2007\end{array}$ \\
\hline Germany ${ }^{(16)}$ & $\mathrm{DH}$ & $\begin{array}{l}5000 \mathrm{M} \\
5000 \mathrm{~F}\end{array}$ & $19-64$ & $\begin{array}{l}4 \\
2\end{array}$ & $\begin{array}{l}4 \\
1\end{array}$ & $\begin{array}{l}11041 \\
8131\end{array}$ & $\begin{array}{l}4112 \\
2511\end{array}$ \\
\hline Austria $^{(16)}$ & EFR & $170 \mathrm{M}$ & $>64$ & 3 & 5 & NA & \\
\hline England $^{(16)}$ & FFQ & $898 \mathrm{~F}$ & $45-54$ & 4 & 2 & 7925 & 2205 \\
\hline Spain $^{(16)}$ & $2 \times 24 \mathrm{hR}$ & $\begin{array}{l}750 \mathrm{M} \\
750 \mathrm{~F}\end{array}$ & $19-59$ & $\begin{array}{l}2 \\
1\end{array}$ & $\begin{array}{l}1 \\
1\end{array}$ & $\begin{array}{l}8925 \\
7047\end{array}$ & \\
\hline Portugal $^{(16)}$ & FFQ & $\begin{array}{l}1200 \mathrm{M} \\
1200 \mathrm{~F}\end{array}$ & $19-64$ & $\begin{array}{l}4 \\
4\end{array}$ & $\begin{array}{l}2 \\
2\end{array}$ & $\begin{array}{l}9937 \\
8731\end{array}$ & $\begin{array}{l}2305 \\
2108\end{array}$ \\
\hline Italy ${ }^{(16)}$ & EFR & $\begin{array}{r}700 \mathrm{M} \\
700 \mathrm{~F}\end{array}$ & $19-64$ & $\begin{array}{r}4 \\
3 \\
\end{array}$ & $\begin{array}{l}2 \\
2 \\
\end{array}$ & $\begin{array}{l}10336 \\
8433 \\
\end{array}$ & $\begin{array}{r}1906 \\
-1604 \\
\end{array}$ \\
\hline Serbia $^{(36)}$ & HFCS & $\begin{array}{l}1173 \mathrm{M} \\
1227 \mathrm{~F}\end{array}$ & $30-60$ & $\begin{array}{l}5 \\
5\end{array}$ & $\begin{array}{l}3 \\
3\end{array}$ & \multicolumn{2}{|c|}{11415 (M\&F) } \\
\hline Poland $^{(75)}$ & $24 \mathrm{hR}$ & $\begin{array}{l}3132 \mathrm{M} \\
3529 \mathrm{~F}\end{array}$ & $20-74$ & $\begin{array}{l}4 \\
3\end{array}$ & $\begin{array}{l}5 \\
4\end{array}$ & $\begin{array}{l}10386 \\
7060\end{array}$ & \\
\hline Hungary ${ }^{(69)}$ & $24 \mathrm{hR}$ & $\begin{array}{l}473 \mathrm{M} \\
706 \mathrm{~F}\end{array}$ & $18-60+$ & $\begin{array}{l}2 \\
2\end{array}$ & $\begin{array}{l}1 \\
1\end{array}$ & $\begin{array}{l}11734 \\
9227\end{array}$ & \\
\hline Estonia $^{(50)}$ & $24 \mathrm{hR}$ & $\begin{array}{l}126 \mathrm{M} \\
190 \mathrm{~F}\end{array}$ & $55-65$ & $\begin{array}{l}4 \\
3\end{array}$ & $\begin{array}{l}8 \\
4 \\
4\end{array}$ & $\begin{array}{l}9567 \\
6888 \\
\end{array}$ & $\begin{array}{l}4804 \\
3217\end{array}$ \\
\hline
\end{tabular}

Fig. 6 Mean (SD) vitamin $D$ intake in $\mu \mathrm{g} / \mathrm{d}$ and mean (SD) energy intake in $\mathrm{kJ} / \mathrm{d}$ for males (M) and females (F) by country and region (separated at - - - from top to bottom, into Scandinavia, Western Europe, Mediterranean and Central and Eastern Europe). Dietary intake method: EFR = estimated food record; $24 \mathrm{hR}=24 \mathrm{~h}$ recall; WFR, weighed food record; $\mathrm{DH}=$ diet history; HFCS = household food consumption survey. NA = not available. Plot shows mean intakes with $95 \%$ confidence

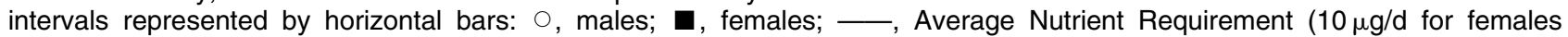
and males)

Western European countries $(136 \mathrm{mg} / \mathrm{d})$ and higher than in Scandinavia and the Mediterranean (107 and $119 \mathrm{mg} / \mathrm{d}$, respectively). The same held for CEE males: the pooled estimate for CEE was $118 \mathrm{mg} / \mathrm{d}$, for other regions it ranged from 93 to $142 \mathrm{mg} / \mathrm{d}$. Both genders in CEE countries had mean intake above the ANR.

The pooled mean vitamin $\mathrm{D}$ intakes for females and males of CEE countries were 3 and $4 \mu \mathrm{g} / \mathrm{d}$, respectively (Fig. 6). These values were comparable to those of the other regions; pooled estimates for females and males were $7 \cdot 8 \mu \mathrm{g} / \mathrm{d}$ in Scandinavia, $2 \cdot 4 \mu \mathrm{g} / \mathrm{d}$ in Western Europe and $3.3 \mu \mathrm{g} / \mathrm{d}$ in Mediterranean countries. The mean intakes in CEE and in other regions were below the ANR with exception of Norway.

Data for the other micronutrients (Cu, iodine, Se and $\mathrm{Zn}$ ) were limited and available for one or two CEE countries and for some population groups only (see Table 2).

The mean $\mathrm{Cu}$ intake in CEE countries was comparable to those in other European countries, $1 \cdot 2-1 \cdot 9 \mathrm{mg} / \mathrm{d}^{(16)}$, except for Serbia, which reported the highest intake. The mean intakes were above the reference values set for $\mathrm{Cu}$. Iodine intake data were available only for Serbia, and the mean intake was in the range of other regions (108-253 $\mu \mathrm{g} / \mathrm{d}$ for males; 101-194 $\mu \mathrm{g} / \mathrm{d}$ for females) $^{(16)}$ being above the ANR. Se intake data for CEE adults were available for Croatia, and the mean intake value was above the range observed in the other regions $(36-73 \mu \mathrm{g} / \mathrm{d}$ for males; $31-55 \mu \mathrm{g} / \mathrm{d}$ for females) ${ }^{(16)}$. The mean intakes for both genders were well above the ANR. Data on mean Zn intake were available for three CEE countries, and the values were similar to those for non-CEE countries $\left(7 \cdot 8-13 \cdot 6 \mathrm{mg} / \mathrm{d}\right.$ for males; $7 \cdot 8-10 \cdot 3 \mathrm{mg} / \mathrm{d}$ for females ${ }^{(16)}$; the average intakes were considerably above the ANR.

Data on micronutrient intakes in CEE children were available from Croatia, Hungary and Serbia. The mean micronutrient intakes in these countries (Table 3) were in range of intakes in children in other European countries $^{(16)}$ : Ca $(600-1381 \mathrm{mg} / \mathrm{d}), \mathrm{Cu}(0 \cdot 8-1.9 \mathrm{mg} / \mathrm{d})$, folate $(138-428 \mu \mathrm{g} / \mathrm{d})$, iodine $(94-209 \mu \mathrm{g} / \mathrm{d}), \mathrm{Fe}(7 \cdot 7-17 \cdot 9 \mathrm{mg} / \mathrm{d})$, Se $(28-110 \mu \mathrm{g} / \mathrm{d})$, vitamin C $(78-197 \mathrm{mg} / \mathrm{d})$, vitamin D $(1 \cdot 2-4.8 \mu \mathrm{g} / \mathrm{d})$ and $\mathrm{Zn}(6 \cdot 5-14.6 \mathrm{mg} / \mathrm{d})$, except for the intake of vitamin $B_{12}$ in Hungary, which was lower in comparison to other European regions $(2 \cdot 9-11 \cdot 8 \mu \mathrm{g} / \mathrm{d})$. In these three CEE countries, mean daily intakes below the ANR were observed for Ca (except in boys in Serbia), folate, vitamin D and for Se in Croatia.

\section{Comparison of micronutrient status}

For micronutrient status most CEE data were available for iodine and Fe status in children. Figures 7 and 8 show the median urinary iodine concentrations and the mean (SD) $\mathrm{Hb}$ concentrations, respectively, for children in Europe. The data on iodine and Fe status were retrieved mainly from the WHO VMNIS database. Exceptions are the data for The Republic of Srpska and Serbia. CEE countries had lower median urinary iodine levels than other European 
Table 2 Mean energy and micronutrient intakes (copper, iodine, selenium and zinc) by Central and Eastern European country in males and females

\begin{tabular}{|c|c|c|c|c|c|c|c|}
\hline Nutrient/country & Dietary intake method & No. of subjects; sex & Age range (years) & Mean & SD & Energy (kJ/d) & SD \\
\hline \multicolumn{8}{|l|}{$\mathrm{Cu}(\mathrm{mg} / \mathrm{d})$} \\
\hline \multirow[t]{2}{*}{ Croatia $^{(52)}$} & FFQ & $183 \mathrm{M}$ & $18-30$ & 2 & 1 & 15955 & 7534 \\
\hline & & $480 \mathrm{~F}$ & & 2 & 1 & 11982 & 5720 \\
\hline \multirow{2}{*}{ Hungary $^{(69)}$} & $24 \mathrm{hR}$ & $473 \mathrm{M}$ & $18-60+$ & 1 & 1 & 11734 & \\
\hline & & $706 \mathrm{~F}$ & & 1 & 0.5 & 9227 & \\
\hline \multirow[t]{2}{*}{ Poland ${ }^{(75)}$} & $24 \mathrm{hR}$ & $3132 \mathrm{M}$ & $20-74$ & 1 & 0.5 & 10386 & \\
\hline & & $3529 \mathrm{~F}$ & & 1 & 0.4 & 7060 & \\
\hline \multirow[t]{2}{*}{ Serbia $^{(36)}$} & HFCS & $1173 \mathrm{M}$ & $30-60$ & 5 & 7 & 11415 (M\&F) & \\
\hline & & $1227 \mathrm{~F}$ & & 4 & 5 & 11415 (M\&F) & \\
\hline \multicolumn{8}{|l|}{ lodine $(\mu \mathrm{g} / \mathrm{d})$} \\
\hline \multirow[t]{2}{*}{ Serbia $^{(36)}$} & HFCS & $1173 \mathrm{M}$ & $30-60$ & 184 & 139 & 11415 (M\&F) & \\
\hline & & $1227 \mathrm{~F}$ & & 144 & 112 & 11415 (M\&F) & \\
\hline \multicolumn{8}{|l|}{$\operatorname{Se}(\mu g / d)$} \\
\hline \multirow[t]{2}{*}{ Croatia $^{(52)}$} & FFQ & $183 \mathrm{M}$ & $18-30$ & 215 & 106 & 15955 & 7534 \\
\hline & & $480 \mathrm{~F}$ & & 141 & 65 & 11982 & 5720 \\
\hline \multicolumn{8}{|l|}{$\mathrm{Zn}(\mathrm{mg} / \mathrm{d})$} \\
\hline \multirow[t]{2}{*}{ Croatia $^{(52)}$} & FFQ & $183 \mathrm{M}$ & $18-30$ & 18 & 9 & 15955 & 7534 \\
\hline & & $480 \mathrm{~F}$ & & 13 & 6 & 11982 & 5720 \\
\hline \multirow[t]{2}{*}{ Hungary ${ }^{(69)}$} & $24 \mathrm{hR}$ & $473 \mathrm{M}$ & $18-60+$ & 10 & 3 & 11734 & \\
\hline & & $706 \mathrm{~F}$ & & 8 & 2 & 9227 & \\
\hline \multirow[t]{2}{*}{ Serbia $^{(36)}$} & HFCS & $1173 \mathrm{M}$ & $30-60$ & 15 & 9 & 11415 (M\&F) & \\
\hline & & $1227 \mathrm{~F}$ & & 12 & 8 & 11415 (M\&F) & \\
\hline
\end{tabular}

$24 \mathrm{hR}, 24 \mathrm{~h}$ recall; HFCS, household food consumption survey.

Reference values: Average Nutrient Requirement (value from Nordic Nutrition Recommendations or US Institute of Medicine) for adults per d: Cu $0 \cdot 7 \mathrm{mg}$; iodine $100 \mu \mathrm{g}$; Se $30 \mu \mathrm{g}$ for females, $35 \mu \mathrm{g}$ for males; $\mathrm{Zn} 5 \mathrm{mg}$ for females, $6 \mathrm{mg}$ for males.

regions: mild iodine deficiency (median urinary iodine $<100 \mu \mathrm{g} / \mathrm{l}$ ) in CEE was found in children and adolescents from Estonia, Hungary, Latvia and Lithuania, whereas children in Albania suffered from moderate iodine deficiency (median urinary iodine $<50 \mu \mathrm{g} / \mathrm{l}$ ). Data from other European countries showed an adequate iodine status (median urinary level $>100 \mu \mathrm{g} / \mathrm{l}$ ) for all countries, except for Italy and Belgium.

The mean $\mathrm{Hb}$ levels in CEE children and adolescents were lower than in other European countries, for which the data were scarce. Mean levels were in general above the cut-off values; only infants in Lithuania were at risk of Fe-deficiency anaemia $(\mathrm{Hb}<110 \mathrm{~g} / \mathrm{l})$, whereas children in Romania had borderline concentration.

CEE data on iodine and Fe status in adults, and on folate, vitamin $\mathrm{B}_{12}$ and $\mathrm{Zn}$ status for all population groups, were too limited to allow between-region comparisons. An overview of the available status data for CEE populations is presented in Table 4.

Median urinary iodine concentration in CEE adults ranged from 51 to $158 \mu \mathrm{g} / \mathrm{d}$, similar to those in other European regions (source: WHO VMNIS database for non-CEE countries; not included in the table). In CEE, mild iodine deficiency (median urinary iodine $<100 \mu \mathrm{g} / \mathrm{l}$ ) was observed in Romanian females. In other regions, both males and females from Italy, France and Germany had mean urinary iodine levels below the cut-off.

Prevalence of iodine deficiency in Europe was recently outlined by Zimmerman and Andersson ${ }^{(35)}$. For CEE countries (data on school-aged children; if not available, pre-school children, adolescents or adults) iodine deficiency was reported in Albania, Estonia, Hungary, Latvia and Lithuania.

For Fe status, CEE data were available only for Serbia ${ }^{(36)}$ and for females from Macedonia ${ }^{(12)}$. Reported mean $\mathrm{Hb}$ concentrations were in the same range as those in other European countries included in the WHO global database (e.g. Spain, France, Denmark and Finland) and above the cut-off value of 120 or $130 \mathrm{~g} / 1$.

Overall, the results on Fe status (Hb levels above the cut-offs) confirm the results on Fe intake for all countries in the present study (except Hungary).

Data on folate status were available for adults in Croatia, Czech Republic and Hungary. Mean serum folate levels in CEE were comparable to those from other European countries (range mean: 16 to $18 \mathrm{nmol} / 1)^{(37-39)}$, with the exception of Norwegian adults $(7 \mathrm{nmol} / \mathrm{l})^{(40)}$. The mean serum folate levels in CEE populations and in other regions were above the cut-off values for both genders, except for Roma mothers in Czech Republic. The findings on folate status are in accordance with observed results on folate intake from the present study for all European regions (except Hungary and Estonian females).

For vitamin $\mathrm{B}_{12}$ status, only one study from CEE was identified. In the Czech Republic reported mean levels of serum vitamin $\mathrm{B}_{12}$ were comparable to those in other European countries, such as Norway ${ }^{(40)}$, and above the reference value $(150 \mathrm{pmol} / \mathrm{l})$. These findings are consistent with the vitamin $\mathrm{B}_{12}$ intake results from the present study (Fig. 4).

Data on $\mathrm{Zn}$ status were available for adults and children in three CEE countries. CEE adults from Czech 


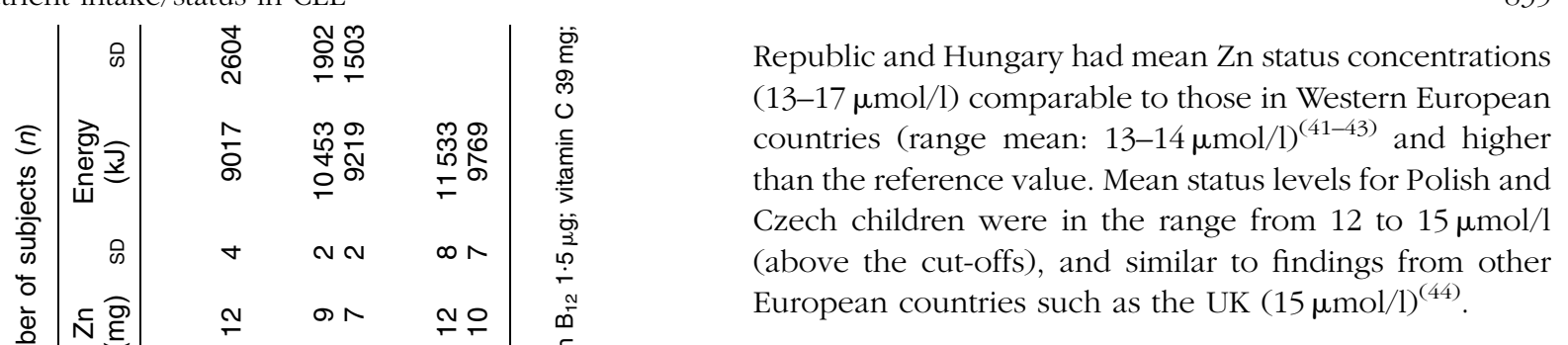

\section{Discussion}

The present study reports the first comprehensive overview of CEE nutritional data using both open access and grey literature sources with a twofold objective: evaluation of intake and status for targeted micronutrients in CEE in comparison to (i) those of other European countries and (ii) the reference values.

From the limited data available, the results of this review show no differences in micronutrient intake and status in CEE populations in comparison to other European regions except for intake of $\mathrm{Ca}$ in adults, and iodine and $\mathrm{Fe}$ status in children (intake and status levels lower in CEE than in non-CEE countries). Comparisons with the intake/status reference values suggest highest risk of inadequacy in intake of vitamin $\mathrm{D}$ in all age ranges, and of $\mathrm{Ca}$, folate and iodine in children.

We collated data using EURRECA's best practice guidance on dietary assessment methods and status biomarkers ${ }^{(30)}$. In general, CEE studies on micronutrient intake and status for all age ranges were scarce: even after being less strict in inclusion criteria, only a few intake studies could be added to the current comprehensive overview. The largest knowledge gap regarding intake refers to children; whereas data on status were scarce for all population groups, with the exception of $\mathrm{Fe}$ and iodine in children. The available studies on micronutrient intake and status studies in CEE countries are diverse with regard to design: they differ in dietary assessment, food composition databases, sampling procedures and age range, and this may confound regional and betweencountry comparisons. Cooperation with the nutritional network from $\mathrm{CEE}^{(17)}$ resulted in obtaining nine studies from grey literature. Even though this was not sufficient to fill an evident knowledge gap in nutritional data from CEE, it added to the existing open sources. However, despite a paucity of data and the variations in methodologies that can influence the true differences in intake ${ }^{(45)}$, some regional variations were observed: it seems that nutritional health in CEE in comparison to other European countries is less favourable but only for certain micronutrients.

Since CEE is less affluent compared with other European regions, it would be interesting to examine the variations in micronutrient intake and status within CEE countries across different socio-economic layers. That would indicate specific subgroups that are most at 


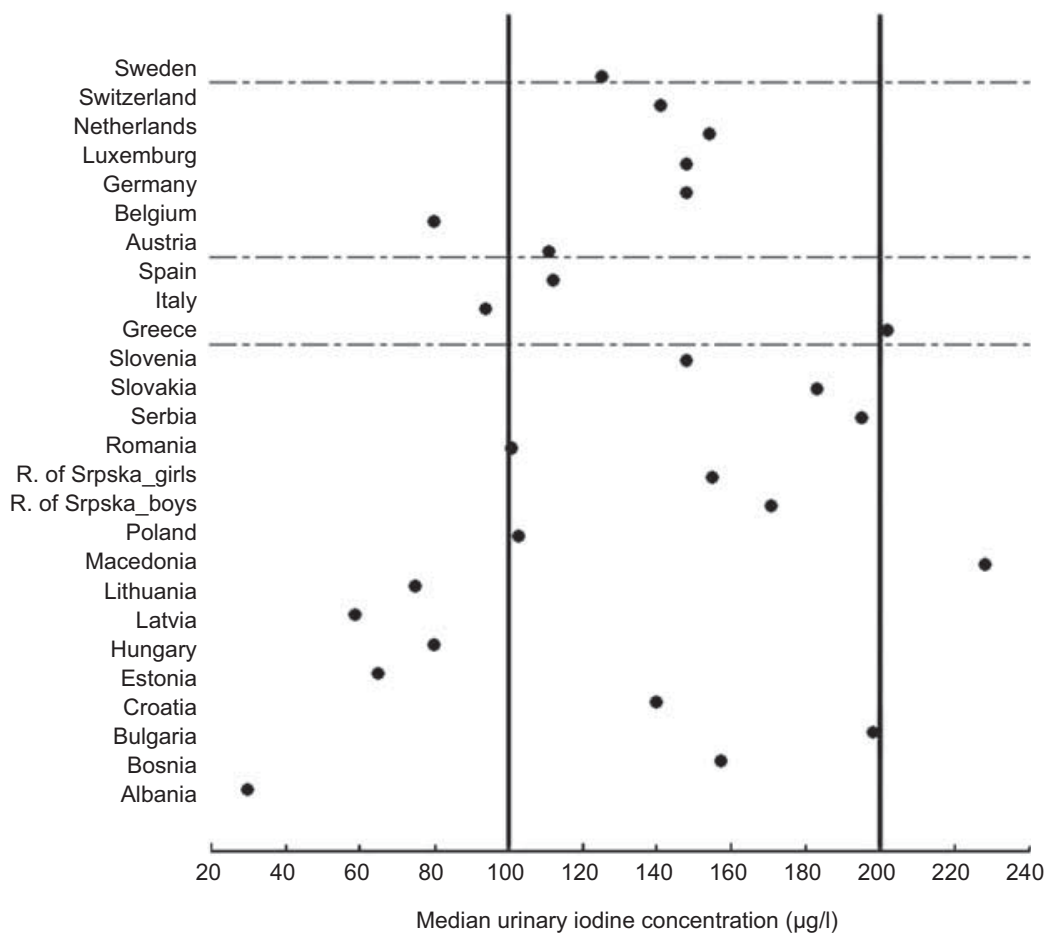

Fig. 7 Median urinary iodine concentration in $\mu \mathrm{g} / \mathrm{l}$ per $\mathrm{d}$ in children and adolescents by country and region (separated at - - from top to bottom, into Scandinavia, Western Europe, Mediterranean and Central and Eastern Europe). —-, Optimal range for median urinary iodine concentration (100-199 $\mathrm{g} / \mathrm{l})$. Source of data: WHO Vitamin and Mineral Nutrition Information System, except for studies from Republic of Srpska ${ }^{(82)}$ and Serbia ${ }^{(80)}$

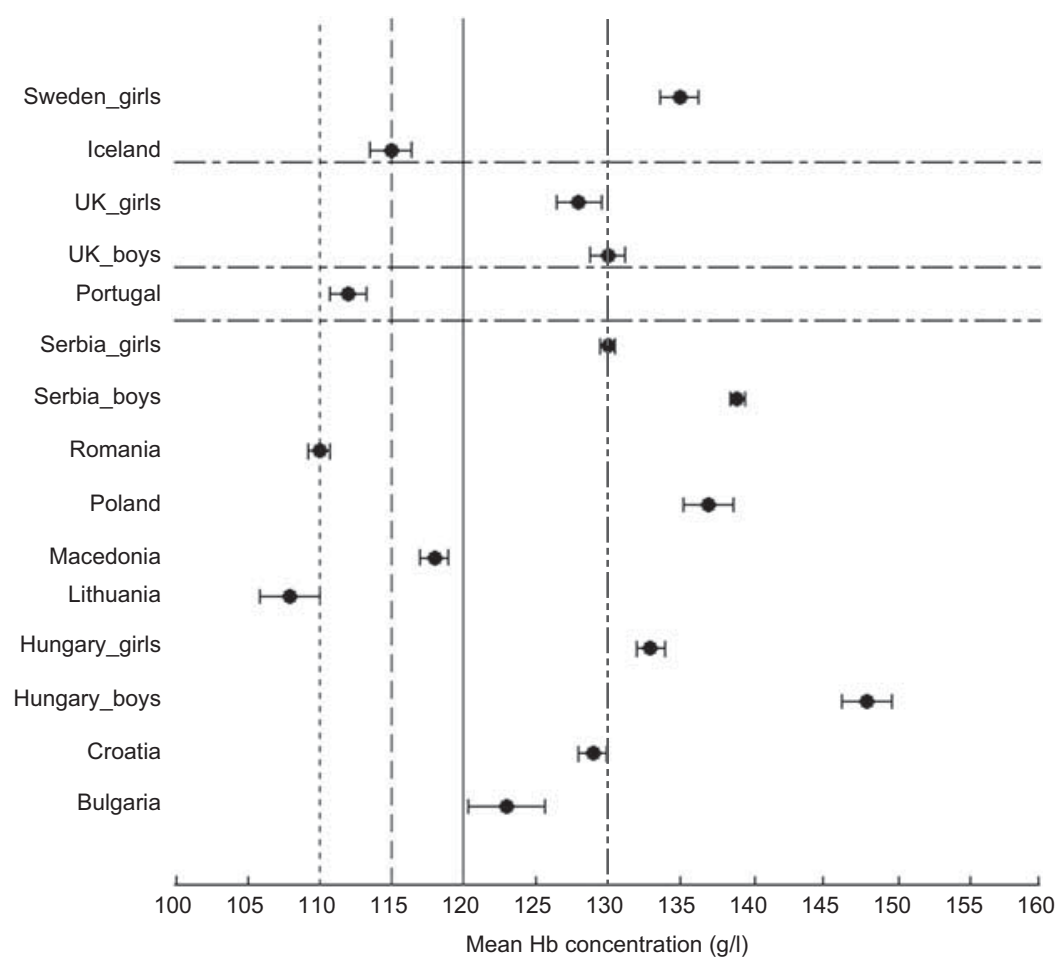

Fig. 8 Mean $\mathrm{Hb}$ concentrations (with $95 \%$ confidence intervals represented by horizontal bars) in g/l per d in children and adolescents by country and region (separated at - - - from top to bottom, into Scandinavia, Western Europe, Mediterranean and Central and Eastern Europe). Age range of the subjects: Bulgaria 2-4 years; Croatia 7-8 years; Hungary 15-19 years; Lithuania 0.5-2 years; Macedonia 0.5-5 years; Poland 10-13 years; Romania 1 year; Serbia 15 years; Portugal 1 year; Iceland 1 year; UK 7-10 years; Sweden 15-16 years. Hb concentration below which anaemia is present: - - , $110 \mathrm{~g} / \mathrm{l}$ (children aged $0.5-5 \mathrm{years}$ );,$--- 115 \mathrm{~g} / \mathrm{l}$ (children aged 5-11 years); — , $120 \mathrm{~g} / \mathrm{l}$ (children aged 12-14 years and females aged $>15$ years); - - - $130 \mathrm{~g} / \mathrm{l}$ (males aged $>15$ years). Source of data: WHO Vitamin and Mineral Nutrition Information System, except for study from Serbia ${ }^{(36)}$ 
Table 4 Micronutrient status by Central and Eastern European country: folate, vitamin $\mathrm{B}_{12}$ and zinc in adults and children, iodine and iron in adults - medians or means and SD

\begin{tabular}{|c|c|c|c|c|}
\hline Country & No. of subjects; sex & Age range (years) & $\begin{array}{l}\text { Mean status marker level } \\
\text { (or median where indicated) }\end{array}$ & SD \\
\hline \multicolumn{5}{|c|}{ Serum folate (mean and so/median; nmol/l) } \\
\hline \multirow{2}{*}{$\begin{array}{l}\text { Croatia }{ }^{(53)} \\
\text { Czech Republic (lactation) }^{(58)}\end{array}$} & $100 \mathrm{~F}$ & $20-30$ & 23 & 9 \\
\hline & $227 \mathrm{~F}$ & 20-35 & $\begin{array}{l}20 \text { (median) Polish; } \\
7 \text { (median) Roma }\end{array}$ & \\
\hline \multirow{2}{*}{ Czech Republic ${ }^{(61)}$} & $126 \mathrm{M}$ & $25-65$ & 14 & 0.4 \\
\hline & $125 \mathrm{~F}$ & & 14 & 0.4 \\
\hline \multirow[t]{2}{*}{ Czech Republic ${ }^{(62)}$} & $250 \mathrm{M}$ & $18-65$ & 14 (median) & \\
\hline & $261 \mathrm{~F}$ & $18-64$ & 14 (median) & \\
\hline \multirow[t]{2}{*}{ Hungary ${ }^{(71)}$} & $1173 \mathrm{M}$ & $>18$ & 20 & 9 \\
\hline & $1386 \mathrm{~F}$ & & 21 & 10 \\
\hline \multicolumn{5}{|l|}{ Urinary iodine (median; $\mu \mathrm{g} / \mathrm{l}$ ) } \\
\hline \multirow[t]{2}{*}{ Poland ${ }^{(78)}$} & $491 \mathrm{M}$ & $>16$ & 121 & \\
\hline & $933 \mathrm{~F}$ & & 106 & \\
\hline Romania ${ }^{\text {(WHO database })}$ & $1387 \mathrm{~F}$ & $15-46$ & 51 & \\
\hline Czech Republic (WHO database) & $254 \mathrm{M} \& \mathrm{~F}$ & $18-66$ & 114 & \\
\hline Bulgaria (pregnancy) ${ }^{(51)}$ & $355 \mathrm{~F}$ & $26 \pm 5$ & 165 & \\
\hline Czech Republic (pregnancy) ${ }^{(59)}$ & $168 \mathrm{~F}$ & $17-41$ & 367 & \\
\hline \multicolumn{5}{|l|}{ Serbia (pregnancy) ${ }^{(80)}$} \\
\hline \multicolumn{5}{|l|}{$\mathrm{Hb}$ (mean and sD; g/l) } \\
\hline \multirow[t]{2}{*}{ Serbia $^{(36)}$} & $544 \mathrm{M}$ & $20-21$ & 148 & 10 \\
\hline & $725 \mathrm{~F}$ & & 128 & 11 \\
\hline Macedonia ${ }^{(\mathrm{WHO}}$ database) & $1018 \mathrm{~F}$ & $15-46$ & 134 & 14 \\
\hline \multicolumn{5}{|c|}{ Serum vitamin $\mathrm{B}_{12}$ (mean and sD/median; pmol/l) } \\
\hline \multirow[t]{2}{*}{ Czech Republic ${ }^{61)}$} & $126 \mathrm{M}$ & $25-65$ & 239 & 7 \\
\hline & $125 \mathrm{~F}$ & & 239 & 7 \\
\hline \multirow[t]{2}{*}{ Czech Republic ${ }^{(62)}$} & $250 \mathrm{M}$ & $18-65$ & 278 (median) & \\
\hline & $261 \mathrm{~F}$ & & 278 (median) & \\
\hline \multicolumn{5}{|l|}{ Serum $\mathrm{Zn}($ mean and $\mathrm{SD} ; \mu \mathrm{mol} / \mathrm{l})$} \\
\hline \multirow[t]{2}{*}{ Czech Republic ${ }^{(63)}$} & $118 \mathrm{M}$ & $36-49$ & 13 & 3 \\
\hline & $118 \mathrm{~F}$ & & 13 & 3 \\
\hline \multirow[t]{2}{*}{ Hungary $^{(71)}$} & $1173 \mathrm{M}$ & $>18$ & 17 & 3 \\
\hline & $1386 \mathrm{~F}$ & & 17 & 3 \\
\hline \multirow[t]{2}{*}{ Czech Republic ${ }^{(63)}$} & 90 boys & 10 & 15 & 3 \\
\hline & 194 girls & & 14 & 3 \\
\hline Poland ${ }^{(79)}$ & 157 boys and girls & 11 & 12 & 2 \\
\hline
\end{tabular}

WHO database, WHO Vitamin and Mineral Nutrition Information System; M, males; F, females.

Proposed cut-off values ${ }^{(20-27,30-33)}$ : serum folate $10 \mathrm{nmol} / \mathrm{l}$ for adults; urinary iodine $100 \mu \mathrm{g} / \mathrm{l}$ for adults, $150 \mu \mathrm{g} / \mathrm{l}$ for pregnant women; $\mathrm{Hb} 130 \mathrm{~g} / \mathrm{l}$ for males, $120 \mathrm{~g} / \mathrm{l}$ for females, $110 \mathrm{~g} / \mathrm{l}$ for pregnant women; serum vitamin $B_{12} 150 \mathrm{pmol} / \mathrm{l}$ for adults; serum $\mathrm{Zn} 10 \mu \mathrm{mol} / \mathrm{l}$ for children and females, $10 \cdot 7 \mu \mathrm{mol} / \mathrm{l}$ for males.

risk of poor nutritional health. For future research, we recommend reviewing grey literature, and its accessibility and reliability need further attention. However, to bring a comprehensive conclusion on the nutritional situation in CEE countries much work is required: for developing tailored, sound, evidence-based nutritional policy, the knowledge gaps and establishing nutritional surveys of comparable quality, covering the diversity of population groups, need to be addressed. The inclusion of CEE countries in pan-European nutritional surveys is highly essential to achieve this objective.

\section{Acknowledgements}

Sources of funding: The work reported herein has been carried out within the EURRECA Network of Excellence (http://www.eurreca.org), which is financially supported by the Commission of the European Communities, specific Research, Technology and Development (RTD) Programme 'Quality of Life and Management of Living Resources', within the Sixth Framework Programme, project no. FP6 036196-2. This report does not necessarily reflect the Commission's views or its future policy in this area. Conflict of interest: The authors declare that they have no conflicts of interest. Authorship responsibilities: R.N. and A.E.J.M.C. conceptualised the paper, collected the data and drafted the manuscript. A.E.J.M.C. supervised the overall work, assisted with analysis and editing of the manuscript. G.E.B., B.R.-V., J.N., M. Golesorkhi, M.W.M., M.N. and Z.S. helped with data collection, reviewing the literature and analysis. M. Gurinović, M. Glibetić, L.S.M., P.v.V., A.G. and L.C.P.G.M.d.G. were involved in development of the study hypothesis, editing the working versions of the manuscript and provided advice regarding interpretation of the results. Acknowledgements: The authors acknowledge the members of the UNU/SCN Network for Capacity Development in Nutrition in Central and Eastern Europe (http://www.agrowebcee. net/ncdn) for the identification and translation of grey literature. It gave added value to the review and enabled a comprehensive overview of available data and implied to knowledge gaps in CEE. 


\section{References}

1. World Health Organization (2008) Closing the Gap in a Generation: Health Equity Through Action on the Social Determinants of Health. Final Report of the Commission on Social Determinants of Health. Geneva: WHO.

2. Mackenbach JP, Kunst AE, Cavelaars AE et al. (1997) Socioeconomic inequalities in morbidity and mortality in western Europe. The EU Working Group on Socioeconomic Inequalities in Health. Lancet 349, 1655-1659.

3. James WP, Nelson M, Ralph A et al. (1997) Socioeconomic determinants of health. The contribution of nutrition to inequalities in health. BMJ 314, 1545-1549.

4. Darmon N (2008) Does social class predict diet quality? Am J Clin Nutr 87, 1107-1117.

5. Walters S \& Suhrcke M (2005) Socioeconomic Inequalities in Health and Health Care Access in Central and Eastern Europe and the CIS: A Review of the Recent Literature. Working Paper 2005/1. Venice: WHO European Office for Investment for Health and Development.

6. World Health Organization (2001) Poverty and Health Evidence and Action in WHO's European Region. Press backgrounder EURO/05/01, Madrid, 11 September 2001. Copenhagen: WHO Regional Office for Europe.

7. Adeyi O, Chellaraj G, Goldstein E et al. (1997) Health status during the transition in Central and Eastern Europe: development in reverse? Health Policy Plan 12, 132-145.

8. Kant AK (2004) Dietary patterns and health outcomes. J Am Diet Assoc 104, 615-635.

9. López-Azpiazu I, Sánchez-Villegas A, Johansson L et al. (2003) Disparities in food habits in Europe: systematic review of educational and occupational differences in the intake of fat. J Hum Nutr Diet 16, 349-364.

10. Bobak M \& Marmot M (1996) East-West mortality divide and its potential explanations: proposed research agenda. BMJ 312, 421-425.

11. Zunft HJ, Ulbricht G, Pokorný J et al. (1999) Nutrition, physical activity and health status in Middle and East European countries. Public Health Nutr 2, 437-441.

12. Parízková J (2000) Dietary habits and nutritional status in adolescents in Central and Eastern Europe. Eur J Clin Nutr 54, Suppl.1, S36-S40.

13. Charzewska J (1994) Gaps in dietary-survey methodology in Eastern Europe. Am J Clin Nutr 59, 1 Suppl., 157S-160S.

14. Cavelaars AE, Doets EL, Dhonukshe-Rutten RA et al. (2010) Prioritizing micronutrients for the purpose of reviewing their requirements: a protocol developed by EURRECA. Eur J Clin Nutr 64, Suppl.2, S19-S30.

15. Viñas BR, Barba LR, Ngo J et al. (2011) Projected prevalence of inadequate nutrient intakes in Europe. Ann Nutr Metab 59, 84-95.

16. Elmadfa I, Meyer A, Nowak V et al. (2009) European Nutrition and Health Report 2009. Forum Nutr 62, 1-405.

17. United Nations University/Standing Committee on Nutrition Network for Capacity Development in Nutrition in Central and Eastern Europe (not dated) Final reports from the 4th (2008) and the 5th (2009) Meetings. http://www. agrowebcee.net/fileadmin/user_upload/NCDNCEE/Final_ report_2008.pdf and http://www.agrowebcee.net/fileadmin/ content/ncdn/files/Report_5th_NCDNCEE_250410-final.pdf (accessed April 2011).

18. Murphy SP, Guenther PM \& Kretsch MJ (2006) Using the dietary reference intakes to assess intakes of groups: pitfalls to avoid. J Am Diet Assoc 106, 1550-1553.

19. Carriquiry AL (1999) Assessing the prevalence of nutrient inadequacy. Public Health Nutr 2, 23-33.

20. UNICEF/United Nations University/World Health Organization (2001) Iron Deficiency Anaemia Assessment, Prevention, and Control. A Guide for Programme Managers. Geneva: WHO; available at http://www.who.int/nutrition/publications/en/ ida_assessment_prevention_control.pdf

21. de Benoist B (2008) Conclusions of a WHO Technical Consultation on folate and vitamin $\mathrm{B}_{12}$ deficiencies. Food Nutr Bull 29, 2 Suppl., S238-S244.

22. Institute of Medicine of the National Academies of Science (1998) Dietary Reference Intake for Thiamine, Riboflavin, Niacin, Vitamin $B_{6}$, Folate, Vitamin $B_{12}$, Pantothenic Acid, Biotin and Choline. Washington, DC: National Academy Press.

23. de Benoist B, Darnton-Hill I, Davidsson L et al. (2007) Conclusions of the Joint WHO/UNICEF/IZiNCG Interagency meeting on zinc status indicators. Food Nutr Bull 28, 3 Suppl., S480-S484.

24. Ristic-Medic D, Pistackova Z, Hooper L et al. (2009) Methods of assessment of iodine status in humans: a systematic review. Am J Clin Nutr 89, issue 6, 2052S-2069S.

25. World Health Organization/UNICEF/International Council for the Control of Iodine Deficiency Disorders (2007) Assessment of Iodine Deficiency Disorders and Monitoring Their Elimination, 3rd ed. Geneva: WHO.

26. Zimmermann MB, de Benoist B, Corigliano S et al. (2006) Assessment of iodine status using dried blood spot thyroglobulin: development of reference material and establishment of an international reference range in iodine-sufficient children. J Clin Endocrinol Metab 91, 4881-4887.

27. Gibson RS (2005) Principles of Nutritional Assessment, 2nd ed. New York: Oxford University Press.

28. The Project Group (editors) (2004) Nordic Nutrition Recommendations 2004, 4th ed. Copenhagen: Nordic Council of Ministers.

29. Doets EL, de Wit LS, Dhonukshe-Rutten RA et al. (2008) Current micronutrient recommendations in Europe: towards understanding their differences and similarities. Eur J Nutr 47, Suppl.1, 17-40.

30. Hooper L, Ashton K, Harvey L et al. (2009) Assessing potential biomarkers of micronutrient status by using a systematic review methodology: methods. Am J Clin Nutr 89, issue 6, 1953S-1959S.

31. Lowe NM, Fekete K \& Decsi T (2009) Methods of assessment of zinc status in humans: a systematic review. Am J Clin Nutr 89, issue 6, 2040S-2051S.

32. Ashton K, Hooper L, Harvey LJ et al. (2009) Methods of assessment of selenium status in humans: a systematic review. Am J Clin Nutr 89, issue 6, 2025S-2039S.

33. Fairweather-Tait SJ \& Harvey LJ (2008) Micronutrient status methods: proceedings of the EURRECA Workshop and Working Party on New Approaches for Measuring Micronutrient Status. Br J Nutr 99, S1-S80.

34. de Bree A, van Dusseldorp M, Brouwer IA et al. (1997) Folate intake in Europe: recommended, actual and desired intake. Eur J Clin Nutr 51, 643-660.

35. Zimmermann MB \& Andersson M (2011) Prevalence of iodine deficiency in Europe in 2010. Ann Endocrinol (Paris) 72, 164-166.

36. Gurinović M, Kadvan A, Vukotić M et al. (2011) The quality of nutrition in schoolchildren and adult members of families. In Yugoslav Study of Atherosclerosis Precursors in Schoolchildren in Serbia: Twenty Years Follow-up, pp. 343-368 [S Nedeljkovic, editor]. Belgrade: Medical Faculty, University of Belgrade; available at http://srbnutrition. info/?page $=$ publications

37. Planells E, Sanchez C, Montellano MA et al. (2003) Vitamins $\mathrm{B}_{6}$ and $\mathrm{B}_{12}$ and folate status in an adult Mediterranean population. Eur J Clin Nutr 57, 777-785.

38. Drogan D, Klipstein-Grobusch K, Wans S et al. (2004) Plasma folate as marker of folate status in epidemiological studies: the European Investigation into Cancer and Nutrition (EPIC)-Potsdam study. Br J Nutr 92, 489-496.

39. Kampman E (2010) Folic acid fortification: good or bad? Presented at WCRF International Conference on Nutrition, 
Physical Activity and Cancer Prevention: Current Challenges, New Horizons, London, UK, 12-13 September 2010.

40. Vogiatzoglou A, Smith AD, Nurk E et al. (2009) Dietary sources of vitamin B-12 and their association with plasma vitamin B-12 concentrations in the general population: the Hordaland Homocysteine Study. Am J Clin Nutr 89, 1078-1087.

41. Thijs L, Staessen J, Amery A et al. (1992) Determinants of serum zinc in a random population sample of four Belgian towns with different degrees of environmental exposure to cadmium. Environ Health Perspect 98, 251-258.

42. Derumeaux H, Valeix P, Castetbon K et al. (2003) Association of selenium with thyroid volume and echostructure in 35- to 60-year-old French adults. Eur J Endocrinol 148, 309-315.

43. Hampel R, Kuhlberg T, Schneider K-P et al. (1997) Serum zinc levels and goitre epidemiology. $Z$ Ernabrungswiss 36, $12-15$.

44. Thane CW, Bates CJ \& Prentice A (2004) Zinc and vitamin A intake and status in a national sample of British young people aged 4-18 y. Eur J Clin Nutr 58, 363-375.

45. Serra-Majem L, Frost Andersen L, Henríque-Sánchez P et al. (2009) Evaluating the quality of dietary intake validation studies. Br J Nutr 102, Suppl. 1, S3-S9.

46. Zimmermann MB, Aeberli I, Melse-Boonstra A et al. (2009) Iodine treatment in children with subclinical hypothyroidism due to chronic iodine deficiency decreases thyrotropin and C-peptide concentrations and improves the lipid profile. Thyroid 19, 1099-1104.

47. Zimmermann MB, Connolly K, Bozo M et al. (2006) Iodine supplementation improves cognition in iodine-deficient schoolchildren in Albania: a randomized, controlled, double-blind study. Am J Clin Nutr 83, 108-114.

48. Toromanovic A \& Tahirovic H (2004) Thyroid volume and urinary iodine excretion in schoolchildren in North-Eastern Bosnia. Eur J Pediatr 163, 270-271.

49. Gatseva P, Vladeva S \& Argirova M (2007) Evaluation of endemic goiter prevalence in Bulgarian schoolchildren: results from national strategies for prevention and control of iodine-deficiency disorders. Biol Trace Elem Res 116 , 273-278.

50. European Commission (2006) AgeingNutrition - Comparative analysis of existing data on nutrition and lifestyle of the ageing population in Europe, especially in the 'new' Baltic, Central and Eastern regions of the Community. Final Implementation Report. http://ec.europa.eu/health/major_ chronic_diseases/diseases/ageing_related_diseases/nutrition/ index_en.htm\#4 (accessed April 2011).

51. Angelova K, Timcheva T, Tenev T et al. (2009) National study of urinary iodine excretion - biomarker of iodine nutrition. Bulgarian J Public Health 1, 66-72.

52. Satalic Z, Baric IC \& Keser I (2007) Diet quality in Croatian university students: energy, macronutrient intakes according to gender. Int J Food Sci Nutr 58, 398-410.

53. Pucarin-Cvetković J, Kaić-Rak A, Matanić D et al. (2006) Dietary habits and folate status in women of childbearing age in Croatia. Coll Antropol 30, 97-102.

54. Mandić-Puljek M, Mandić ML, Perl A et al. (2005) Calcium intake, food sources and seasonal variations in Eastern Croatia. Coll Antropol 29, 503-507.

55. Colić-Barić I, Kajfez R, Satalić Z et al. (2004) Comparison of dietary habits in the urban and rural Croatian schoolchildren. Eur J Nutr 43, 169-174

56. Cvijetić S, Barić IC, Bolanca S et al. (2003) Ultrasound bone measurement in children and adolescents: correlation with nutrition, puberty, anthropometry, and physical activity. J Clin Epidemiol 56, 591-597.

57. Boylan S, Welch A, Pikhart H et al. (2009) Dietary habits in three Central and Eastern European countries: the HAPIEE study. BMC Public Health 9, 439.
58. Rambousková J, Dlouhý P, Krízová E et al. (2009) Health behaviors, nutritional status, and anthropometric parameters of Roma and non-Roma mothers and their infants in the Czech Republic. J Nutr Educ Behav 41, 58-64.

59. Korenek A \& Prochazka M (2008) Iodine in early pregnancy - is there enough? Biomed Pap Med Fac Univ Palacky Olomouc Czech Repub 152, 97-99.

60. Milerová J, Cerovská J, Zamrazil V et al. (2006) Actual levels of soy phytoestrogens in children correlate with thyroid laboratory parameters. Clin Chem Lab Med 44, 171-174.

61. Mayer O, Filipovský J, Dolejsová M et al. (2006) Mild hyperhomocysteinaemia is associated with increased aortic stiffness in general population. J Hum Hypertens 20, 267-271.

62. Veselá K, Pavlíková M, Janosíková B et al. (2005) Genetic determinants of folate status in Central Bohemia. Physiol Res 54, 295-303.

63. Kvicala J \& Jiránek V (1999) INAA of serum zinc of inhabitants in five regions of the Czech Republic. Biol Trace Elem Res 71-72, 21-30.

64. Vendt N, Talvik T, Leedo $S$ et al. (2009) The reference limits and cut-off value for serum soluble transferrin receptors for diagnosing iron deficiency in infants. Int J Lab Hematol 31, 440-446.

65. Vendt N, Grünberg H \& Leedo S (2007) Prevalence and causes of iron deficiency anemias in infants aged 9 to 12 months in Estonia. Medicina (Kaunas) 43, 947-952.

66. European Centre on Health of Societies in Transition \& World Health Organization (1999) Nutrition and Lifestyle in the Baltic Republics. Summary Report. Copenhagen: WHO Regional Office for Europe.

67. Biró L, Regöly-Mérei A, Nagy K et al. (2003) Dietary habits of schoolchildren: representative survey in metropolitan elementary schools: Part 2. Ann Nutr Metab 51, 454-460.

68. Sandor J (2007) Report on periconceptional folic acid supplementation for Hungary. EUROCAT special report. http:// ec.europa.eu/health/archive/ph_threats/non_com/docs/ eurocat_en.pdf (accessed April 2011).

69. Rodler I, Bíró L, Greiner E et al. (2005) TáplálkozásivizsgálatMagyarországon, 2003-2004 (Dietary survey in Hungary, 2003-2004). Orvosi Hetilap 146, 1781-1789.

70. Bhattoa HP, Bettembuk P, Ganacharya S et al. (2004) Prevalence and seasonal variation of hypovitaminosis $D$ and its relationship to bone metabolism in community dwelling postmenopausal Hungarian women. Osteoporos Int 15, 447-451.

71. Biró G, Antal M \& Zajkás G (1996) Nutrition survey of the Hungarian population in a randomized trial between 1992-1994. Eur J Clin Nutr 50, 201-208.

72. Kiudeliene R, Griniūte R \& Labanauskas L (2008) Prognostic value of reticulocyte hemoglobin content to diagnose iron deficiency in 6-24-month-old children. Medicina (Kaunas) 44, 673-677.

73. Bodzek P, Olejek A \& Zamłyński J (2006) Iodine excretion with urine and thyrotrophic hormone concentration in normal and complicated pregnancies in the industrial region of iodine deficiency. Wiad Lek 59, 612-617.

74. Januszewska R \& Viaene J (2007) Food Consumption of Low Income Groups in Poland and Belgium. Warsaw: Warsaw University of Life Sciences Press.

75. Wartość energetyczna i odżywcza diety dorosłych mieszkańców Polski. Wynikiprogramu WOBASZ. Unpublished data from the National Multicentre Health Survey (WOBASZ). More details about the study in Rywik S, Kupoeoeæ W, Piotrowski W et al. (2005) Wieloośrodkowe ogólnopolskie badanie stanu zdrowia ludności - projekt WOBASZ. Założenia metodyczne oraz logistyka. Kardiologia Polska 63, 6 Suppl. 4

76. Sekula W, Nelson M, Figurska K et al. (2005) Comparison between household budget survey and 24-hour recall data in a nationally representative sample of Polish households. Public Health Nutr 8, 430-439. 
77. Szybinski Z, Golkowski F, Buziak-Bereza M et al. (2008) Effectiveness of the iodine prophylaxis model adopted in Poland. I Endocrinol Invest 31, 309-313.

78. Gołkowski F, Buziak-Bereza M, Trofimiuk M et al. (2007) Increased prevalence of hyperthyroidism as an early and transient side-effect of implementing iodine prophylaxis. Public Health Nutr 10, 799-802.

79. Schlegel-Zawadzka M, Zachwieja Z, Huzior-Baajewicz A et al. (2002) Comparative analysis of zinc status, food products' frequency intake and food habits of 11-year-old healthy children. Food Addit Contam 19, 963-968.
80. Institute of Public Health of Serbia \& UNICEF (2009) National Survey of the Biological Impact of Universal Salt Iodisation in the Population of Serbia 2007. Belgrade: UNICEF Belgrade; available at http://www.unicef.org/ serbia/SALT_IODISATION_SERBIA_2007.pdf

81. Krajcovicova-Kudlackova M, Babinska K, Valachovicova M et al. (2007) Vitamin C protective plasma value. Bratisl Lek Listy 108, 265-268.

82. Lolic A \& Prodanovic N (2008) The Republic of Srpska Iodine Deficiency Survey 2006. Hormones (Athens) 7, 163-169. 